\title{
LA PROTECCIÓN AL VIAJERO FRENTE A LOS DAÑOS SUFRIDOS DURANTE UN VIAJE COMBINADO ${ }^{1}$
}

\author{
JOSÉ MIGUEL SÁNCHEZ BARTOLOMÉ ${ }^{2}$ \\ Abogado. Doctor en Derecho.
}

\section{Resumen:}

La actual regulación española en materia de viajes combinados se rige por el RD Legislativo 1/2007, de 16 de noviembre, si bien su actual contenido habrá de modificarse en breve, tras los cambios introducidos por la nueva Directiva de la Unión Europea 2015/2302/UE.

Actualmente, existe un régimen de responsabilidad específico por los daños ocasionados a los consumidores en la ejecución deficiente del contrato, por efectuar modificaciones al viaje, contrariando el contenido pactado -antes del inicio del itinerario o durante el mismo-, o a causa de la cancelación del viaje. Esto lleva a analizar los criterios para identificar al responsable de la ejecución defectuosa, así como para la determinación del quantum indemnizatorio, a la vista de las circunstancias que pueden darse. También se recogen las medidas de protección a los viajeros frente a la insolvencia del organizador.

Pero no siempre que surge un daño existe una responsabilidad por parte del organizador o la agencia de viajes. Sin embargo, no por ello pueden abstenerse de actuar. Por el contrario, la regulación impone la obligación de prestar asistencia al viajero.

Por último, se hace una breve referencia a los servicios de viajes vinculados, definiendo a esta novedosa figura, diferenciada de los viajes combinados, pero para la que también se prevén una serie de medidas de protección al consumidor que contrata por medio de esta modalidad. agencia

Palabras clave: viaje combinado, responsabilidad, asistencia, viajero, organizador,

\section{Abstract:}

The current Spanish regulation on combined travel is governed by RD 1/2007, 16 November, although its current content will have to be modified shortly, following the changes introduced by the new Directive of the European Union 2015/2302 / EU.

Currently, there is a specific liability regime for damages caused to consumers in the defective execution of the contract, for making changes to the trip, contrary to the agreed content -before or during the itinerary-, or because its cancellation. Therefore, it is necessary the analysis of the criteria to identify the responsible for the defective execution, as well as for the determination of the compensation, in view of the circumstances that may arise. It also includes measures to protect travelers against the insolvency of the trip organizer.

\footnotetext{
1 El presente trabajo se realiza en el marco del Proyecto de Investigación TRAZAR.2 (DER2016-76936-R), desarrollado por la Universidad de Zaragoza, con mi agradecimiento a la Dra. Profesora $\mathrm{D}^{\mathrm{a}}$ Mercedes Zubiri de Salinas por permitirme tomar parte en el mismo.

${ }^{2}$ josemiguelsanchezbartolome@gmail.com
} 
But not every time a damage arises there is a responsibility on the part of the organizer or the travel agency. However, they can not refrain from acting. On the contrary, the regulation imposes the obligation to assist the traveler.

Lastly, a brief reference is made to linked travel services, defining this figure, differentiated from package travel, but also foresees a series of consumer protection measures that it contracts through this modality.

Keywords: travel package, responsibility, assistance, traveler, organizer, travel agency

\section{INTRODUCCIÓN}

La contemporánea generalización del turismo de masas ha permitido la aparición de una actividad económica de esencial trascendencia para la economía europea, y particularmente en la española, que se plasma en las cifras que la definen. Así, los viajes y el turismo aportaron al país 119.011 millones de euros en el año 2015 -el 11,1\% del PIB de España $^{3}$-, y generando en el conjunto del Estado un total de 2.804 .407 puestos de trabajo en el cuarto semestre de $2016^{4}$.

Esta generalización de la actividad turística permite la existencia de las agencias de viajes y turoperadores, cuya función es la de intermediar en la contratación de los diversos servicios que el usuario precisará a lo largo de su itinerario ${ }^{5}$, confeccionando un producto que se instrumenta en los denominados "contratos de viaje combinado", que se sustancian en paquetes turísticos, elaborados a cambio de un precio global para el consumidor ${ }^{6}$, presentados $^{\circ}$ a través de programas u ofertas publicitarias, y que se concretan en las condiciones generales de los contratos. Con su actividad, facilitan una labor que, de tener que llevarse a cabo por el propio turista, le resultaría enormemente complejo, y económicamente más gravoso.

En el mercado de la Unión Europea existen aproximadamente 6.000 turoperadores y agencias de viajes, estimándose que aproximadamente el $80 \%$ de ellas ofrecen a la venta paquetes turísticos. Hay además, unas 72.000 agencias de viajes, que en un $99 \%$ de ocasiones son pequeñas y medianas empresas, de las que el $92 \%$ son microempresas de menos de siete empleados ${ }^{7}$.

\footnotetext{
${ }^{3}$ Fuente: Instituto Nacional de Estadística. Cuenta satélite del turismo de España. Aportación del turismo a la economía española - Año 2015. Disponible en: http://www.ine.es/dyngs/INEbase/es/operacion.htm?c estadistica_C\&cid $=1254736169169 \&$ menu=ultiDatos\&idp $=1254735576863$.

${ }^{4}$ Fuente: Ministerio de Energía, Turismo y Agenda Digital. Nota de coyuntura de la Encuesta de Población Activa. IV Trimestre 2016. Disponible en: http:/estadisticas.tourspain.es/es-ES/estadisticas/ otrasestadisticas/empleoturistico/encuestapoblacion/Notas $\% 20 \mathrm{de} \% 20$ Coyuntura/NotaEmpleoTurismo $\% 2$ 04T2016.pdf.

${ }^{5}$ La cantidad de actividades que se pueden contratar con un turoperador, en el seno de un contrato de viaje combinado es innumerable, pero pueden resumirse básicamente en servicios de transporte, alojamiento, manutención, la contratación de guías turísticos, la adquisición de entradas para actividades y eventos culturales o deportivos, entre otros muchos.

${ }^{6}$ MOYA JIMÉNEZ, A., Reclamaciones de derecho de consumo. Aspectos prácticos, Ed. Wolters Kluwer, Hospitalet de Llobregat, 2016, pág. 275.

7 Estadísticas estructurales económicas de Eurostat, presentadas en el Anexo 7 de los documentos de trabajo elaborados por la Comisión Europea en relación con la propuesta de la nueva Directiva, el 9 de julio de 2013.
} 
Como se ha visto, esta actividad se presta por parte de dos actores fundamentales: por un lado, los turoperadores-también denominados organizadores o mayoristas- y por otra las agencias de viajes -que se denominan también minoristas o detallistas-. La principal diferencia entre ambas entidades radica en el producto comercializado y, fundamentalmente, en su destinatario. Para los turoperadores, que organizan de forma no ocasional los viajes combinados, generalmente sus destinatarias son las agencias de viajes. Para estas, que comercializan los paquetes turísticos, sus clientes son los usuarios finales o consumidores de servicios turísticos ${ }^{8}$, también denominados viajeros.

Según se configura en la regulación, y como se verá más adelante, el viaje combinado, puede definirse como aquel que ofrece al usuario al menos dos de las siguientes tres prestaciones: el transporte, el alojamiento, $u$ otros servicios que constituyan una parte significativa del viaje (como visitas guiadas a monumentos, comidas, entradas para eventos...), que se combinan en un único producto de viaje, de cuya correcta ejecución asume la responsabilidad el organizador.

Al igual que cualquier otra actividad humana, la realización de un viaje turístico supone la generación del riesgo de que se produzcan inconvenientes de todo tipo. En ocasiones, las incidencias se generarán por una inadecuada acción u omisión de quienes lo comercializan, pero otras veces, el problema surgirá a causa del propio viajero o, simplemente por la concurrencia de circunstancias fortuitas, que no sean achacables a nadie. La propia complejidad de los viajes combinados, que conllevan la coordinación de las actividades turísticas de los viajeros, casi siempre a una gran distancia del lugar de celebración del contrato, así como el tipo de actividades que en él se desarrollan, son factores que sin duda incrementan el riesgo de que una inconveniencia ocurra.

Si a todo lo anterior se une la dificultad de identificar al responsable cuando se produce el incumplimiento o el cumplimiento defectuoso de alguno de los servicios que integran el paquete, no queda sino cuestionarse cuál es la situación en la que se encuentra un viajero que sufre algún tipo de incidencia relacionada con su viaje, así como qué régimen de obligaciones compele a quienes comercializan el paquete turístico, en función de si la incidencia la generaron ellos mismos o fue producto de una situación ajena a su propio ámbito de actuación, teniendo en cuenta que quienes se encargan de prestar los distintos servicios que engloba el paquete turístico son generalmente empresas distintas de aquellas con las que el cliente ha contratado directamente.

Todo ello va a ser objeto de análisis a lo largo del presente texto, atendiendo además a la evaluación de los daños morales aplicados a la actividad del viaje combinado, y la actividad aseguradora que se genera de forma accesoria al contrato. Sin embargo, no se va a limitar a los supuestos de responsabilidad del organizador del viaje combinado, sino que también se atenderán aquellas situaciones que, surgidas sin que medie una ejecución deficiente del viaje combinado, requieren de la colaboración o asistencia o de la agencia de viajes al viajero.

Se hará mención por último a la situación específica de los servicios de viaje vinculados, teniendo en cuenta la particularidad del régimen que los regula, al tratarse de un tipo de actividad que no presenta las características propias de los viajes combinados.

${ }^{8}$ ARCARONS I SIMÓN, R. y CASANOVAS IBÁÑEZ, O., "De la jurisprudencia amenazante a la legislación atenazante: análisis del Real Decreto Legislativo 1/2007, de 16 de noviembre, y su incidencia en la organización, programación y venta de viajes combinados", en Revista Aragonesa de Administración Pública, n 32, 2008, pág. 437. 


\section{MARCO REGULATORIO}

Tanto la normativa de la Unión Europea como la legislación nacional se han ocupado de regular la figura del viaje combinado, en ambos casos desde una perspectiva protectora de los derechos de los consumidores y usuarios, siguiendo un esquema en el que la regulación europea genera un estándar básico de protección para quienes contratan un viaje combinado, que los Estados miembros han de garantizar o mejorar. Este es el caso de España, que asume un régimen propio, que mejora al europeo en términos de protección al consumidor.

El punto de partida de la regulación europea en materia de viajes combinados se encuentra en el art. 169 TFUE", que en su apartado 1, impone a la Unión Europea "promover los intereses de los consumidores y garantizarles un alto nivel de protección". Este mandato llevó al Consejo de la Unión Europea a adoptar la Directiva 90/314/CEE ${ }^{10}$, con la pretensión de generar una serie de normas comunes en todos los Estados miembros, elaborando una normativa en una actividad desigualmente regulada hasta ese momento, que generaba consecuentemente la indefensión de los viajeros.

Además, esta norma incorporaba entre sus objetivos contribuir a la eliminación de los obstáculos existentes respecto "a la libre prestación de servicios en relación con los viajes combinados y distorsiones en la competencia entre los operadores establecidos en Estados miembros". No obstante, y a pesar de que pasó a dotarse al contrato de un marco jurídico completo, inexistente hasta ese momento, terminó por resultar insuficiente para solventar muchas de las situaciones surgidas en la actividad comercial, especialmente las relacionadas con el surgimiento de las nuevas tecnologías y la contratación por medios electrónicos.

Es por ello que la Unión Europea promulgó la nueva Directiva 2015/2302/UE ${ }^{11}$, un instrumento de modernización de las normas sobre los viajes combinados que figuraban en la anterior Directiva, generando de esta forma una nueva regulación capaz de superar las limitaciones y costes innecesarios generados por unas disposiciones obsoletas, así como de colmar las lagunas jurídicas existentes en las medidas de protección a los consumidores, especialmente a quienes adquieren sus viajes combinados por medio de Internet ${ }^{12}$.

Los Estados miembros disponen de un plazo, que finalizó el 1 de enero de 2018, para incorporar a sus propios marcos legales el contenido de la nueva norma, que deberá ser de aplicación en todo caso a partir del 1 de julio de 2018. En este sentido, según el artículo 4 de la Directiva, ésta tiene carácter obligatorio en todos sus términos, de modo que los Estados miembros no podrán mantener en sus legislaciones internas disposiciones que la contradigan, de las que se derive un nivel inferior de protección para los viajeros ${ }^{13}$.

\footnotetext{
${ }^{9}$ Tratado de Funcionamiento de la Unión Europea. DOUE n ${ }^{\circ}$ L 83, de 30 de marzo de 2010.

${ }^{10}$ Directiva 90/314/CEE del Consejo, de 13 de junio de 1990, relativa a los viajes combinados, las vacaciones combinadas y los circuitos combinados. DOCE n L 158, de 23 de junio de 1990.

${ }^{11}$ Directiva (UE) 2015/2302, de 25 de noviembre, del Parlamento Europeo y del Consejo, relativa a los viajes combinados y a los servicios de viaje vinculados, por la que se modifican el Reglamento (CE) n. ${ }^{\circ}$ 2006/2004 y la Directiva 2011/83/UE del Parlamento Europeo y del Consejo y por la que se deroga la Directiva 90/314/CEE del Consejo. DOUE L-326, de 11 de diciembre de 2015

${ }^{12}$ Teniendo en cuenta lo establecido por el Tribunal de Justicia de la Unión Europea en su Sentencia de 30 de abril de 2002, As. Club Tour, Viagens e Turismo SA/Alberto Carlos Lobo Gonçalves Garrido y Club Med Viagens Ld., C-400/00, en cuya virtud no debe existir diferencia entre los servicios reservados de manera presencial y los comercializados por medios electrónicos.

${ }^{13}$ En palabras de Véra Jourová, Comisaría de Justicia, Consumidores e Igualdad: "If you plan your holidays you should not have to worry about insufficient legal protection. This is why new EU rules
} 
Un aspecto importante de la nueva regulación europea de viajes combinados es que no incluye en su ámbito de aplicación a los viajes de corta duración, entendiendo como tales los de menos de 24 horas que no incluyan alojamiento, así como los viajes combinados o los servicios de viaje vinculados que solamente se ofrecen o facilitan de manera ocasional y sin ánimo de lucro a un grupo limitado de viajeros. El motivo declarado de esta exclusión es la menor necesidad de protección de este tipo de viajeros, así como evitar cargas innecesarias para los empresarios ${ }^{14}$.

En cuanto a España, la regulación sustantiva de los viajes combinados se introdujo por primera vez a través de la Ley de Viajes Combinados ${ }^{15}$, que traspuso al ordenamiento nacional la Directiva 30/314/CEE, pasando de esta forma a dotar a este tipo de contrato de consumo de una normativa material específica, de la que carecía hasta su publicación.Dicha Ley fue derogada, pasando a incorporar su contenido al Real Decreto Legislativo 1/2007, de 16 de noviembre -en adelante, TRLGDCU ${ }^{16}$-, dentro de su Libro IV (art. 150 a 165). Esta norma, que refunde en un único texto la antigua Ley General para la Defensa de los Consumidores y Usuarios y las normas de transposición de las directivas comunitarias dictadas en materia de protección de los consumidores y usuarios, incorporó entre éstas a la Ley de Viajes Combinados. Muy probablemente, el contenido del TRLGDCU deberá ser nuevamente modificado a causa de la promulgación de la nueva norma europea ${ }^{17}$.

La norma española diferencia dos figuras distintas dentro de los viajes combinados. Por un lado, se denomina organizador a la persona física o jurídica que organiza de forma no ocasional viajes combinados y los vende $\mathrm{u}$ ofrece en venta, directamente o por medio de un detallista (art. 151.1.b TRLGDCU). El organizador es también denominado en ocasiones mayorista, o turoperador. Por otro lado, el detallista es la persona física o jurídica que vende $\mathrm{u}$ ofrece en venta el viaje combinado propuesto por un organizador (art. 151.1.c TRLGDCU). También se denomina minorista o agente de viajes.

El propio concepto de viaje combinado viene establecido tanto en los arts. 2 y 3 de la Directiva (UE) $n^{\circ}$ 2015/2302, como en el art. 151 TRLGDCU, cuando concurren los siguientes elementos: (i) Duración mínima del viaje de 24 horas o pernoctación; (ii) Venta del viaje con arreglo a un precio global ${ }^{18}$; (iii) Concurrencia de, al menos, 2 de los 3 elementos

will soon cover over 120 million holidaymakers who book combined travel online: adapting the EU rules on package travel to the digital age. Travellers will clearly know what they are buying and what their rights are, especially if something goes wrong during their holidays. These new rules also support the travel industry that will benefit from less administrative burden and much-needed legal clarity." Fuente: UE. 28 de mayo de 2015. Disponible en http://europa.eu/rapid/press-release_IP-155063 en.htm?locale $=$ en.

${ }^{14}$ Considerando $19^{\circ}$ de la Directiva (UE) 2015/2302

${ }^{15}$ Ley 21/1995, de 6 de julio, para la regulación de los Viajes Combinados. BOE $n^{\circ} 161$, de 7 de julio de 1995 .

${ }^{16}$ Real Decreto Legislativo $1 / 2007$, de 16 de noviembre, por el que se aprueba el texto refundido de la Ley General para la Defensa de los Consumidores y Usuarios y otras leyes complementarias. BOE $\mathrm{n}^{\circ} 287$, de 30 de noviembre de 2007.

${ }^{17}$ Para ello, el Ministerio de Sanidad, Servicios Sociales e Igualdad lanzó desde el 4 hasta el 19 de abril de 2017 la Consulta Pública previa sobre un anteproyecto de Ley de modificación del TRLGDCU, para realizar la trasposición de la Directiva (UE) 2015/2302, en la que se recabó la opinión de los sujetos y las organizaciones más representativas potencialmente afectados por la futura norma.

${ }^{18} \mathrm{El}$ art. 150.2 TRLGDCU establece de manera expresa que el hecho de facturar por separado los servicios que integran el viaje no exime al profesional de la aplicación de la Ley. 
siguientes: a) Transporte, b) Alojamiento, y c) Otros servicios turísticos no accesorios del transporte o del alojamiento y que constituyan una parte significativa del viaje $\mathrm{e}^{19}$.

La jurisprudencia española ha definido reiteradamente al viaje combinado como aquel que tiene por objeto la realización de un viaje turístico o vacacional, mediante la prestación de un conjunto de múltiples servicios que integran un "paquete turístico" retribuido mediante un precio global, de tal forma que "el contrato debe entenderse como un todo unitario y no como una mera suma de prestaciones que pudieran considerarse aisladamente y sólo cuando el cliente ha podido disfrutar y ha recibido todas y cada una de las prestaciones del programa, será cuando pueda decirse que se ha cumplido el fin económico-jurídico perseguido por el cliente al contratar y se habrá conseguido asi satisfacer el crédito del demandante por parte del obligado al cumplimiento de la obligación", tal y como afirma la Sentencia de la Audiencia provincial de Badajoz de 25 de octubre de 2004.

Sin embargo, tal y como enuncia la Sentencia de la Audiencia Provincial de Huesca de 11 de diciembre de 2012, no hay razones para dejar de aplicar las normas generales en materia de contratos, y la consiguiente diferencia entre el incumplimiento total del contrato (non adimpleticontractus) y el cumplimiento defectuoso del contrato no cumplido debidamente -en cantidad, calidad, manera o tiempo-, o cumplido parcialmente (non ritead impleti contractus). Así lo defienden también otra cantidad de Sentencias recaídas sobre la materia, como las de la Audiencia Provincial de Madrid de 29 de abril del 2009, 12 de mayo del 2010, o 16 de abril de 2012.

Según la doctrina ${ }^{20}$, la relación jurídica concertada entre el viajero y las agencias de viajes debe calificarse como un contrato de obra, materializado en la realización de un viaje turístico como resultado completo y definido en sus aspectos más relevantes, empleando para ello medios propios o concertados, de manera que su responsabilidad por la obtención del resultado comprometido se extiende no sólo a las consecuencias de la propia actuación, sino que alcanza a las derivadas de las colaboraciones concertadas por ella con otras personas o entidades, de acuerdo con lo que dispone el artículo 1596 del Código Civil. Así por ejemplo, si un pasajero se lesiona a causa de un resbalón en el transcurso de un crucero, dispondrá de la posibilidad de demandar al turoperador, a la agencia de viajes o al prestador del servicio, como razonaba la Sentencia de la Audiencia Provincial de Barcelona de 22 de febrero de 2016.

En este mismo sentido se manifestó la Sentencia de la Audiencia Provincial de Guadalajara de 4 de febrero de 2005, que consideraba al contrato de viaje combinado un contrato de obra, siendo el propio viaje el resultado completo a proporcionar por el turoperador, de forma que, atendiendo al art. 1596 del Código Civil, su responsabilidad se extiende a las consecuencias derivadas de la actuación de las colaboraciones concertadas por aquel con otras personas o entidades.

${ }^{19}$ La interpretación de qué considera la Directiva como "proporción significativa" la aporta el Considerando Dieciocho de la propia norma, al indicar que "si otros servicios turísticos representan el 25 \% o más del valor de la combinación, debe considerarse que constituyen una proporción significativa del valor del viaje combinado o del de los servicios de viaje vinculados". Al no quedar incorporada al articulado, cabe entender que se trata de una prescripción interpretativa, de forma que cabe entender que prestaciones y servicios de un valor inferior pudieran considerarse igualmente significativos.

${ }^{20}$ MARTÍNEZ ESPÍN, P., "Responsabilidad en el contrato de viaje combinado. La solución definitiva. Comentario a la STS de 20 de enero de 2010", en Revista CESCO de Derecho de Consumo, $\mathrm{n}^{\circ}$ 2/2012, pág. 131. Disponible en: https://www.revista.uclm.es/index.php/cesco/article/view/50. 


\section{DAÑOS CAUSADOS POR UNAEJECUCIÓN DEFICIENTE DEL CONTRATO: RESPONSABILIDAD}

A la vista del actual marco legal, en primer lugar se debe analizar la regulación que aplica a los supuestos en que se generan daños por una ejecución deficiente del contrato por parte de quien los ha comercializado. A este respecto, los principales problemas de responsabilidad se plantean como consecuencia de que quienes se encargan de prestar tales servicios son empresas distintas de aquellas con las que el cliente ha contratado, siendo introducidas por la agencia de viajes para el cumplimiento de las obligaciones contractuales asumidas frente al cliente ${ }^{21}$.

Como premisa de partida, hemos de considerar que la principal obligación del mayorista, la agencia de viajes y sus representantes no es otra que la prestación de los servicios en las condiciones acordadas ${ }^{22}$. En España, el régimen de responsabilidad por el incumplimiento de dicha obligación aparece recogido en el art. 162 TRLGDCU, por el cual el viajero, en su condición de usuario, tiene derecho a ser indemnizado por los daños y perjuicios demostrados como consecuencia de la ejecución defectuosa del viaje.

En definitiva, y como bien expone la Sentencia de la Audiencia Provincial de Cádiz de 4 de abril de 2016, este régimen de responsabilidad "no es otra cosa que el reflejo de la establecida con carácter general en el art. 1.101 del Código Civil a tenor del cual quedan sujetos a la indemnización de daños y perjuicios causados los que en el cumplimiento de sus obligaciones incurrieren en dolo, negligencia o morosidad y los que de cualquier modo contravinieren el tenor de aquellas, corriendo por tanto a cargo del actor ${ }^{23}$ (...), acreditar la existencia de la acción u omisión determinante de la misma".

\subsection{La información al viajero}

Así pues, el primer paso que debe abordarse es identificar en qué consisten los servicios ofertados, y cuál es el alcance de las condiciones pactadas, por lo que no debe olvidarse quela formalización del contrato de viaje combinado ha de efectuarse por escrito, identificando a las partes así como al asegurador -en caso de que así se contrate-, incorporando con precisión las características del viaje, e indicando los medios de transporte que se van a emplear, los lugares de alojamiento, los itinerarios, fechas y lugares de partida y

${ }^{21}$ En términos de la Sentencia de la Audiencia Provincial de Zaragoza de 1 de abril de 2005, "el detallista acepta frente al consumidor el plan organizativo y detalles del viaje confeccionado por la mayorista y así lo ofrece al público que a ella (minorista) acude, por lo que frente al consumidor aparece como oferente de un producto cuyo entramado interno de elaboración, no le es -ni tiene por qué-ser expuesto al consumidor, quien contrata directamente con la minorista, sin obligación -ni posiblemente posibilidad-de indagar las relaciones y pactos internos entre mayorista y minorista".

${ }^{22}$ Conforme al Considerando 22 de la Directiva (UE) 2015/2302, la principal característica de los viajes combinados es la existencia de un empresario que es responsable, en cuanto organizador, de la correcta ejecución del viaje combinado en su conjunto.

${ }^{23}$ En el caso abordado en la Sentencia, se ejercitaba una acción de reclamación contra la mayorista organizadora de un viaje combinado, por los daños y perjuicios derivados de la caída sufrida en el restaurante de un barco cuando disfrutaba de un crucero. 
llegada de cada actividad ${ }^{24}$, además de, por supuesto, el precio y las modalidades de pago. Así se prevé en el art. 5 de la Directiva (UE) 2015/2302, así como el art 154 TRLGDCU.

Pero no sólo en la redacción del contrato encontramos los elementos que vinculan al comercializador. De acuerdo a lo establecido en el art. 152 TRLGDCU, la agencia de viajes tiene el deber precontractual de poner a disposición de los consumidores un programa o folleto informativo, en el que se exponga de forma clara, precisa y completa el contenido del viaje, su precio final y completo, el importe del anticipo, las responsabilidades, cancelaciones y demás información relevante, quedando vinculada de la adecuación del servicio prestado al contenido del folleto, que pasa a incorporarse al contenido del propio contrato.

Este precepto general tiene dos salvedades, previstas en el art. 153TRLGDCU,(i) Que los cambios en dicha información se hayan comunicado claramente por escrito al consumidor y usuario antes de la celebración del contrato y tal posibilidad haya sido objeto de expresa mención en el programa-oferta, y (ii) Que se produzcan posteriormente modificaciones, previo acuerdo por escrito entre las partes contratantes. El art. 6.1 de la Directiva impone que el contenido del contrato de viaje combinado no se modifique salvo que las partes contratantes acuerden expresamente lo contrario.

Además, debe tenerse en cuenta que el viajero recibe la información y el asesoramiento en relación con su viaje directamente desde la minorista, y prácticamente siempre en ausencia del turoperador, siendo además a quien se abona el importe del viaje contratado, por lo que también debe alcanzarle la responsabilidad por la identidad entre la cantidad y calidad de los servicios ofertados y los realmente disfrutados por el viajero.

Así lo manifestó la Sentencia de la Audiencia Provincial de Guipúzcoa de 11 de noviembre de 2008, en un caso en el que la propia agencia de viajes se lamentaba de la escasa o nula fiabilidad de los datos ofrecidos por el turoperador como si resultase algo ajeno a ella. Como afirmaba el voto particular manifestado en la Sentencia, "ella era la que atendia, quien atendió al consumidor y ella era la que se responsabilizaba frente a sus clientes de que lo ofertado se ajustara a la realidad, no que se estuviera ante una mera aproximación. Si la mayorista era de fiar o no, recaía la responsabilidad exclusivamente en la agencia de viajes".

Tampoco corresponde al consumidor efectuar una evaluación propia de la verosimilitud de las condiciones que aparecen en el folleto informativo publicado, por mucho que éstas contradigan " a las opiniones de otras personas sobre las características de los hoteles que aparecen en Internet", como acertadamente indicó la ya citada Sentencia de la Audiencia Provincial de Huesca de 11 de diciembre de 2012.

Esto implica que la propia redacción contractual, conjuntamente con el contenido de la publicidad emitida en relación con el paquete turístico comercializado, debiera permitir identificar claramente en qué momento se está ante una ejecución deficiente del contrato, qué tipo de incumplimiento se está produciendo, permitiendo con mayor facilidad analizar las consecuencias de la ejecución defectuosa respecto de alguno de los servicios pactados.

De esta forma, en supuestos como el abordado en la Sentencia de la Audiencia Provincial de Madrid de 25 de enero de 2017, en la que se ofertaba un hotel que no admitía menores de edad, alojando finalmente a los viajeros en un hotel de la misma categoría, prestaciones, servicios, ubicación y precio, dentro del mismo enclave turístico, pero que no

${ }^{24}$ SÁNCHEZ CALERO, F. (Actualizado por SÁNCHEZ-CALERO GUILARTE, J.) Principios de Derecho Mercantil, 22ª Edición, Ed. Thomson Reuters Aranzadi, Cizur Menor, 2017, pág. 277. 
cumplía con el requisito ofertado, el juzgador entendió que "esa característica no es irrelevante y guarda directa relación con la clase de vacaciones elegida, pues se presume un mayor sosiego, distintas actividades lúdicas e incluso el uso y disfrute de instalaciones con otras pautas de conducta entre adultos", ameritaba la estimación de la demanda, y la consiguiente indemnización a los consumidores.

También en la Sentencia de la Audiencia Provincial de Valencia de 19 de mayo de 2000 , en el que el folleto publicitario indicaba que existía un seguro de accidentes en pista, que el actor había concertado, cuando en realidad la entidad no había suscrito tal seguro, sino uno de asistencia sanitaria, de alcance más limitado, la resolución alcanzada por el tribunal fue condenatoria para el organizador del viaje, con el argumento de que el contenido de la publicidad será exigible por los consumidores o usuarios, aun cuando no figuren expresamente en el contrato celebrado, o en el documento o comprobante recibido

A esta información debe unírsele, tal y como afirmó la Sentencia de la Audiencia Provincial de Barcelona de 27 de junio de 2000, la obligación de informar al viajero de la probabilidad de que el viaje contratado pueda sufrir algún cambio por causas que, como empresa del sector, deba conocer de forma anticipada al inicio del itinerario, de forma que éste disponga de todos los datos necesarios sobre las características del viaje contratado ${ }^{25}$.

Sin embargo, esta obligación de información no finaliza con la celebración del contrato, sino que se mantiene durante todo el momento en el que existe vínculo entre organizador, agencia y viajero. Así se asevera en la Sentencia de la Audiencia Provincial de Sevilla de 7 de abril de 2016, en la que tras la contratación de un viaje a las islas Seychelles, en el que se habían adquirido unas clases de buceo, las playas se encontraban cerradas por varios ataques de tiburón con víctimas mortales, de los que no se informó a los consumidores, que se vieron privados en el destino de la realización de dichas actividades, por unas circunstancias que debieran haber sido advertidas por el organizador, dado que este disponía de un representante en el destino.

\subsection{Identificación del responsable de la ejecución defectuosa}

Una vez comprobado cuál es el régimen prestacional pactado y publicitado, el siguiente paso es identificar a la persona o personas, sean estas físicas o jurídicas, cuya acción u omisión llevó al incumplimiento de los términos acordados. Resulta importante, en primer término, para determinar si el incumplimiento es achacable a la agencia de viajes, al mayorista, a alguno de los proveedores, o si por el contrario, es por causa del propio viajero.

Para ello, se deberán analizar los hechos que concurren a cada caso concreto, para poder establecer la correspondiente relación de causalidad entre la acción o inacción de alguna de las partes y las consecuencias dañosas surgidas.

Así, por ejemplo, la Sentencia de la Audiencia Provincial de Las Palmas de 24 de noviembre de 2003 condenó a la agencia de viajes y a su aseguradora a indemnizar a un viajero que sufrió un accidente de esquí durante un viaje combinado, por entender que el hecho de que la víctima siguiese las instrucciones que le proporcionaba la monitora, hacía a ésta responsable del percance, y no al propio esquiador ni a la persona que se chocó con él en la pista.

${ }^{25}$ En aquel litigio concreto, la probabilidad de que la zona a la que se dirigía el viaje se viese afectada por un huracán. 
También en un caso analizado por la Sentencia de la Audiencia Provincial de Madrid de 4 de mayo de 2010, en el cual durante un itinerario hacia la sabana de Tanzania realizado en un vehículo jeep, incluido en el paquete del viaje contratado, unos viajeros sufrieron un accidente con lesiones, al perder el conductor del vehículo el control del mismo. La Audienciaentendió que existía una ejecución deficiente del contrato,puesto que elmayorista se obligó "como consecuencia del contrato a llevar a cabo losservicios de transporte o traslado de los viajeros durante su estancia en el destino y es obvioque no lo hizo de forma satisfactoria, cuando los demandantes sufrieron un accidente detráfico con resultado de lesiones que les impidió continuar disfrutando del viaje previsto".

En cuanto al régimen de responsabilidad de prestadores y comercializadores de servicios, la nueva Directiva europea establece que quien ha de responder de la correcta prestación de los servicios de viaje es el organizador, con independencia de que hayan sido ejecutados por él o por otros prestadores de servicios, y sin perjuicio de su derecho de repetición contra el verdadero responsable, según impone a los Estados miembros el art. 13.1 de la Directiva.

Por su parte, corresponde al minorista responder por los incumplimientos cuando el organizador esté establecido fuera del Espacio Económico Europeo, salvo que pruebe que éste cumple con las obligaciones impuestas en la norma en relación con las obligaciones impuestas a los organizadores en los Capítulos IV (responsabilidad por la ejecución del viaje) y $\mathrm{V}$ (protección frente la insolvencia), según el art.20 de la Directiva.

Asimismo, al viajero se le asigna desde el art. 13.2 de la Directiva un papel activo en la identificación de las ejecuciones deficientes del programa prestacional pactado, al indicar que le corresponderá informar al organizador sin demora indebida de las faltas de conformidad detectadas durante la ejecución de un servicio de viaje, teniendo en cuenta las circunstancias de cada caso.

Según el considerando 34 de la norma europea: "El incumplimiento de esta obligación puede ser tenido en cuenta al determinar la reducción del precio o la indemnización por daños y perjuicios adecuada en aquellos casos en que dicha notificación hubiera evitado o reducido los daños y perjuicios", obligando el art. 7.2.a) a hacer constar este deber del viajero en el contrato.

Obviamente, la protección alcanza también al caso de que el viajero haya intentado ponerse en contacto con el turoperador o su representante al advertir la deficiencia, sin conseguir establecer con éxito la comunicación. En tal caso, lo trascendente es la ejecución errónea "contra la voluntad del cliente, y la falta de respuesta a su intento de desistir del viaje y reclamación formulada, sin aceptación por parte del consumidor expresa ni tácita de las nuevas condiciones, no acomodadas a las iniciales", tal y como afirmó la Sentencia de la Audiencia Provincial de Madrid de 25 de enero de 2017.

En su reclamación, el viajero puede optar entre contactar directamente con elturoperador, o hacerlo a través del minorista con el que contrató el viaje combinado, que queda obligado a transmitir sin demora el mensaje al mayorista. A efectos del cumplimiento de términos o de plazos de prescripción, el acuse de recibo por el minorista se considerará efectuado por el organizador, tal y como establece el art.15 de la Directiva.

Una vez recibida la información de que "cualquiera de los servicios del viaje no se ejecuta de conformidad con el contrato de viaje combinado", el organizador deberá subsanar la falta de conformidad, y si no lo hace en un plazo razonable establecido por el viajero, éste 
podrá subsanarlo por su cuenta, y estará habilitado para solicitar el reembolso de los gastos necesarios. Sin embargo, no resultará necesario que el viajero especifique un plazo si el organizador se niega a subsanar la falta de conformidad o si se precisa una solución inmediata $(\operatorname{art} .13 .3)^{26}$.

Si para el organizador la subsanación de la falta de conformidad es "imposible" o en caso de que le "suponga un coste desproporcionado", deberá reducir el precio del viaje, e incluso indemnizarpor los daños y perjuicios causados (art. 13.3 y 14 de la Directiva).El viajero solo podrá rechazar las fórmulas alternativas propuestas si no son comparables a lo acordado en el contrato de viaje combinado o si la reducción de precio concedida es inadecuada (art.13.5). Si además el viaje incluye transporte de pasajeros, podrá repatriarse al viajero sin dilaciones y sin coste para éste (art.13.6).

Sin embargo, el art. 13.1 in fine de la Directiva europea abre la puerta a que los Estados miembros amplíen la responsabilidad a los minoristas, con la finalidad de no reducir la protección con que cuentan en la actualidad los viajeros en algunos países -como es el caso de España-. De esta forma, la nueva regulación europea viene a extender al ámbito de la Unión Europea un principio que ya se encontraba plasmado en la normativa nacional española, el de la responsabilidad solidaria del turoperador y la agencia frente al viajero que contrató sus servicios, acabando con la dificultad que para el viajero suele entrañar la distinción e identificación de ambos, a los que se unen los prestadores del servicio de transporte y el alojamiento.

Por su parte, la regulación española ya había previsto esta mejora en la protección de la posición del consumidor, incorporando al TRLGDCU por el art. 162.1 27 , que indica que cuando el incumplimiento de las obligaciones pactadas sea por causa de alguno de los prestadores de los servicios contratados, tanto el turoperador como la agencia de viajes detallista habrán de responder como responsables frente al cliente que contrató, pudiendo a su vez repetir en este caso contra el prestador que incumplió.

Este régimen de responsabilidad solidaria ha sido históricamente aplicado de forma mayoritaria en la jurisprudencia española. Sin embargo, se pueden encontrar Sentencias que no admitieron la solidaridad, como la de la Audiencia Provincial de Barcelona de 14 de marzo de 2000, o de la Audiencia Provincial de Valladolid de 10 de febrero de 2006, bajo el argumento de que la derogada Ley de Viajes Combinados sólo consagraba el principio de solidaridad "cuando concurran conjuntamente en el contrato diferentes organizadores o detallistas, cualquiera que sea su clase y las relaciones que existan entre ellos", lo cual significa que la solidaridad solo existía, por un lado, entre organizadores y, por otro lado, entre minoristas, pero no entre organizadores y detallistas.

No obstante, la Sentencia del Tribunal Supremo de 20 de enero de $2010^{28}$ resolvió esta discrepancia,condenando de forma solidaria a la minorista y al turoperador. En su resolución,

\footnotetext{
${ }^{26}$ Por ejemplo, si el retraso de un autobús facilitado por el organizador obliga al viajero a tomar un taxi para llegar a su vuelo a tiempo (Considerando 34 de la Directiva).

27 Art. 162.1 TRLGDCU: “(...) La responsabilidad frente al consumidor será solidaria de cuantos empresarios, sean organizadores o detallistas, concurran conjuntamente en el contrato, cualquiera que sea su clase y las relaciones que existan entre ellos, sin perjuicio del derecho de repetición de quien responda ante el consumidor frente a quien sea imputable el incumplimiento o cumplimiento defectuoso del contrato en función de su respectivo ámbito de gestión del viaje combinado (...)".

${ }^{28}$ Con relación a un accidente de circulación en Turquía, por culpa imputada judicialmente al conductor del autocar en el que se trasladaban unos viajeros, durante un viaje combinado que habían
} 
el Tribunal Supremo aunó los fundamentos que hasta entonces se encontraban dispersos en la jurisprudencia menor para justificar la responsabilidad solidaria de agencias de viajes y turoperadores.

El primero de estos fundamentos se basa en la Sentencia del propio Alto Tribunal de 23 de julio de 2001, acerca de la derogada Ley de Viajes Combinados -cuyo tenor es incorporado al TRLGDCU en su art. 162-, en la que calificaba como compraventa la relación entre agencia detallista y consumidor, afirmando que:"en conclusión, la relación existente entre la agencia minorista y el usuario es la propia derivada de un contrato de compraventa, actuando la agencia como vendedora, en nombre y por cuenta propia, de los productos creados por ella o por una tercera agencia mayorista...", y no a modo de comisionistas o mandatarios del mayorista u organizador, puesto que la agencia, como minorista, asume su propio riesgo.

Además, la Sentencia considera que la responsabilidad solidaria es la mejor fórmula, puesto que tiene como finalidad la protección del consumidor, entendiendo que cualquier otra solución es susceptible de generar confusión en la parte más débil de la relación contractual, el propio consumidor, quien se vería en la obligación de decidir a quién demanda. En casos de dificultad, sería aconsejable que el consumidor pudiera dirigir su demanda contra todos y que sea el tribunal quien establezca los términos de la imputación.

Otro de los argumentos empleados por el Tribunal Supremo en su Sentencia es que el hecho de que tanto el mayorista que oferta el programa como el minorista que recibe el encargo y el operador turístico que ofrecen el servicio final se benefician de los resultados económicos del contrato debe suponer que todos ellos asuman los riesgos que derivan del mismo. Por ello, el cliente debe estar en disposición de dirigirse contra todos o contra cualquiera de ellos, sin perjuicio del derecho de repetición.

Esta obligatoriedad también alcanza a determinadas situaciones en las que no existe beneficio económico concreto, como el caso de premios consistentes en un viaje combinado a clientes preferentes de una agencia de viajes o mayorista. La Sentencia de la Audiencia Provincial de Zaragoza de 13 de noviembre de 2012, entendió que tal caso, pese a que éstas no obtuvieron rendimiento económico por la promoción concreta, no cabía duda que "en la relación comercial inicial de la que esta era un mero apéndice, sí hubo rendimiento económico, a lo que había de sumarse el prestigio comercial obtenido por ambas con la promoción", generando en consecuencia la obligación de responder ante el viajero, además en forma solidaria.

A ello se suma que la propia normativa de protección de los consumidores establece como regla general la solidaridad cuando sean varias las personas que deben responder frente a un consumidor por los daños causados, tal y como establece el art. 27.2 TRLGDCU, en cuya virtud "si en la producción del daño concurrieren varias personas, responderán solidariamente ante los perjudicados". Además, la finalidad de la regulación europea "es la protección del consumidor y éste en las Directivas que establecen regulaciones especiales para determinados contratos, excepto en la de Viajes combinados, goza de la garantía expresa de la solidaridad, lo que no impide que las responsables condenadas puedan ejercitar las correspondientes acciones de regreso contra quien haya causado verdaderamente el daño o parte del mismo".

contratado. 
Finalmente, entiende que debe protegerse la confianza y la apariencia para el consumidor. El propio Tribunal afirma que "Este es un nuevo argumento que va a favorecer la protección del consumidor, que es lo que se trata de obtener con las normas que establecen la responsabilidad solidaria por los daños causados en un viaje combinado. De este modo resulta lógico que el minorista responda frente al consumidor y para no dejarle desamparado, la regla de la solidaridad le va a permitir repetir contra el mayorista".

Por todo lo expuesto, el Alto Tribunal concluye que "esta Sala se adscribe decididamente por la tesis de estimar la responsabilidad solidaria entre organizador $y$ detallista, pues ninguna duda ofrece que la Ley de Viajes Combinados como la Directiva que incorpora pretende una mayor protección a los consumidores y obviamente la solidaridad responde mejor a esa protección, con lo cual ya nos encontramos con un elemento interpretativo cual es el relativo al espíritu y finalidad de la norma que nos lleva a entender la solidaridad (...)".

Con gran claridad, la Sentencia de 3 de mayo de 2012 de la Audiencia Provincial de Madrid justificaba así la responsabilidad solidaria: "La apuesta legislativa es favorecer la posición del consumidor, que es amparado mediante la técnica de la solidaridad. De este modo se favorece que pueda demandar donde contrató, sin tener que afrontar el costo de foros inverosimiles (transportistas, hosteleros o mayoristas extranjeros), y sin el riesgo de que se le oponga como excepción responsabilidades de terceros de muy complicada discusión. Los beneficios de la coincidencia de intereses empresariales que organiza el mayorista involucrando a los prestadores de servicios y a agencias de viajes, tienen como correlato la obligación de responsabilidad solidaria, que no impide que luego se hagan las reclamaciones oportunas precisamente en el marco de esa cooperación empresarial".

Siguiendo este mismo razonamiento, la Sentencia de la Audiencia Provincial de Madrid de 25 de enero de 2017, declaraba la existencia de responsabilidad de la mayorista y la agencia de viaje por el cambio en el alojamiento respecto al ofertado en el programa del viaje combinado, a causa de una sobreventa en el hotel, por supuesto, sin perjuicio de las acciones que pudiera entablar contra esos terceros, con los que los clientes perjudicados no mantenían relación jurídica alguna.

Finalmente, para el caso de errores debidos a defectos técnicos en el sistema de reservas, el art. 21 de la nueva Directiva europea prevé que el empresario responda por ellos, salvo que sean imputables al viajero o a circunstancias inevitables y extraordinarias, interpretadas en los términos previstos en la propia Directiva 2015/2302, que define en su art. $3.12^{\circ}$ a estas circunstancias como "situaciones fuera del control de la parte que la alega y cuyas consecuencias no habrían podido evitarse incluso si se hubieran adoptado todas las medidas razonables".

Esta previsión coincide con la actual jurisprudencia española. En efecto, ante el caso de un fallo en el sistema informático de reservas que supuso una modificación del hotel en el que alojaban unos viajeros, la Sentencia de la Audiencia Provincial de Valencia de 28 de julio de 2008, el juzgador entendió que no era relevante el motivo de la ejecución deficiente, bastando con la constatación de que se produjo un error para deducir la existencia de responsabilidad por parte de la parte demandada. También se manifestó en este mismo sentido la Sentencia de la Audiencia Provincial de Barcelona de 5 de junio de 2013, en un caso en el que el organizador remitió un correo electrónico confirmando la reserva, cuando lo cierto es que debido a un error informático en realidad no había completado el proceso de reserva. 


\subsection{La modificación de elementos esenciales del viaje. La cancelación del viaje combinado. El derecho de desistimiento}

En ocasiones, el organizador podrá conocer la existencia de alguna causa que implique la modificación de alguno de los elementos esenciales del viaje, incluido el precio. Esto podrá ocurrir con anterioridad a que el viajero inicie su itinerario, pero podrá también ocurrir con posterioridad al inicio del viaje. Ante dichas eventualidades, la regulación existente prevé una serie de alternativas, tanto para el propio turoperador como para el viajero.

Así, en caso de que el mayorista conozca de alguna causa de modificación parcial del viaje, deberá comunicarlo al consumidor que contrató a través de la agencia minorista, de manera inmediata, indicando además cómo afectan al precio, según establece el art. 158.1 TRLGDCU y 11.1 de la Directiva. Frente a esto, le corresponde al cliente optar entre el derecho a resolver el contrato sin coste alguno, si así lo decide, o aceptar las modificaciones que se han efectuado en el viaje, las cuales deben detallarse por escrito, debiendo ser de cantidad equivalente o superior. La contestación del cliente a la agencia deberá comunicarse en el plazo de tres días desde que le haya sido notificada la modificación (art. 158.2). En caso de no contestar, se entenderá que opta por resolver el contrato sin que por ello tenga que sufrir penalización alguna.

En aquellos casos en los que el cliente opte por la resolución del contrato, el párrafo tercero del art. 159.3 TRLGDCU realiza una remisión al art. 76 del propio Texto Refundido, en cuanto a los plazos y condiciones para el reintegro de las cantidades abonadas por el viajero, considerando como dies a quo para el cómputo de los plazos el momento de la notificación del viajero de su opción por la resolución o aquel en el que se produjeran las circunstancias determinantes de la cancelación.

Por su parte, el mismo art. 76 impone que el reintegro se efectúe en el plazo más breve que sea posible, nunca superior a 30 días desde el desistimiento, recayendo sobre el empresario la carga de la prueba sobre el cumplimiento del plazo de devolución, facilitando al consumidor la eventual reclamación de los daños y perjuicios que su retraso le haya podido ocasionar.

La norma europea establece además una limitación del 8 por ciento a los posibles incrementos del precio que el prestador de servicios puede aplicar antes del inicio del viaje, por encima de la cual el viajero dispone de la posibilidad de cancelar el contrato sin que ello implique el pago de penalización alguna (art. 10.2 Directiva). Además, esta posibilidad únicamente se puede ejercitar si se prevé expresamente en el contrato el derecho del viajero a una reducción en el importe de su viaje. En tal caso, el contrato de viaje combinado indicará el modo en que han de calcularse las revisiones del precio.

El art. 10.1 de la Directiva permite únicamente el incremento unilateral de precio bajo tres circunstancias, vinculadas a los cambios de precio de: (i) El transporte de pasajeros derivado del coste del combustible o de otras fuentes de energía; (ii) El nivel de los impuestos o tasas sobre los servicios de viaje incluidos en el contrato, exigidos por terceros que no están directamente involucrados en la ejecución del viaje combinado; y (iii) Los tipos de cambio aplicables al viaje combinado. El incremento de precio deberá haberse notificado al viajero con una antelación de al menos veinte días sobre el inicio del viaje combinado, debiendo notificarse al viajero en un soporte duradero, y de modo claro y comprensible (art. 10.3).

Pero la norma no se limita a establecer el derecho de resarcimiento del viajero en la cuantía adelantada. Adicionalmente, el propio TRLGDCU en su art. 159.3 prevé un régimen 
de responsabilidad de la agencia, cuya cuantía indemnizatoria se modula atendiendo a la antelación sobre la fecha de inicio con la que se comunicó al consumidor la cancelación del viaje, de forma que cuanto más cercana a su inicio fuera la comunicación, mayor será la indemnización que deba afrontar la agencia de viajes.

En concreto, la norma prevé que el cliente deberá ser indemnizado, en un mínimo del cinco por del precio total del viaje contratado, si el incumplimiento se produce entre los dos meses y quince días inmediatamente anteriores a la fecha prevista para la realización del viaje, el diez por ciento del precio total del viaje, si se produce entre los quince y tres días anteriores, o el veinticinco por ciento del precio total del viaje, si este incumplimiento se produce en las cuarenta y ocho horas anteriores al inicio del viaje.

Además, habrá de ser resarcido en las cantidades abonadas, pudiendo optar por la realización de otro viaje combinado de calidad equivalente o superior, cuando la agencia esté en disposición de suministrarlo. Si las condiciones del nuevo viaje fueran inferiores, la agencia estará obligada a reintegrar al viajero la diferencia entre las cantidades ya pagadas y el precio del nuevo viaje.

Por otra parte, si el organizador no suministra o comprueba que no puede suministrar parte importante de los servicios previstos en el contrato una vez iniciado el viaje, la agencia deberá adoptar todas las decisiones necesarias para que se efectúen las prestaciones necesarias, asegurando la adecuada continuación del viaje, sin incremento de precio para el viajero. En caso de que estas nuevas prestaciones fuesen de un valor inferior al acordado, la agencia deberá abonar al consumidor la diferencia de valor entre las prestaciones contratadas y las efectivamente suministradas.

Si el cliente continúa su viaje con las soluciones dadas por el turoperador se considerará que las acepta tácitamente, pero si las soluciones adoptadas por el organizador fueran inviables o el viajero no las aceptase por motivos razonables, aquél debe facilitar el regreso del consumidor al punto de salida del viaje o a cualquier otro que ambos hayan convenido, sin suplemento alguno de precio, y asumiendo las consecuencias indemnizatorias correspondientes (art. 161 TRLGDCU).

Este término "razonable" genera una situación de debilidad e incertidumbre al consumidor, porque ¿quién decidirá la razonabilidad de un motivo? ¿cómo se ponderará en cada caso concreto? Además, la infinita casuística que puede presentarse en cada itinerario, que pueden llevar a cada viajero concreto a tomar decisiones diametralmente opuestas por motivos igualmente razonables. Hay que tener en cuenta que estas decisiones las asume el viajero desde una posición de especial debilidad (muchas veces a gran distancia de su domicilio, en un país cuyo idioma desconoce, en ocasiones en entornos que dificultan enormemente su regreso a casa...), y que permiten al turoperador una enorme capacidad de influencia en la toma de decisiones del viajero.

Este juicio de razonabilidad debe efectuarse por el juzgador en cada caso concreto. De esta forma, la Audiencia Provincial de Madrid en su Sentencia de 23 de abril de 2004, decidió que ante una grave avería del barco durante un crucero, no cabía exigir que los demandantes aceptasen razonablemente el regreso en el mismo navío averiado, tal y como había propuesto el turoperador, por lo que condenó a éste a indemnizar a los viajeros con el importe que habían abonado por los billetes de avión de regreso a su ciudad de origen.

Por su parte, la Sentencia de la Audiencia Provincial de Madrid de 24 de enero de 2017 entendió que no resultaba razonable indemnizar a un viajero que no había solicitado el 
regreso inmediato al punto de partida del viaje ante un incumplimiento del hotel en el que se alojaba, y que posteriormente había solicitado la compensación por el itinerario completo, afirmando que debiera haber sido transportado a España tras haber solicitado la rescisión del contrato en una hoja de reclamaciones del representante del mayorista en el destino.

El juzgador entendió que no cabía atender dicha solicitud, por no resultar razonable deducir de dicha expresión el deseo de volver a casa del demandante, especialmente porque continuó en el hotel intentando que se les prestara el servicio contratado, por lo que debía entenderse que "Su postura real era la de que se subsanaran las deficiencias en la prestación del servicio y no la de dar por concluido el viaje"

En último lugar, debe abordarse otra de las situaciones previstas en la normativa, acerca de las consecuencias que se derivan de la cancelación del contrato de forma unilateral por parte del organizador del viaje o la agencia. En este supuesto de incumplimiento absoluto, que implica la inaplicación por completo del régimen prestacional pactado, el art. 159.1 TRLGDCU prevé que si la cancelación contractual se hubiese producido por causa no imputable al consumidor, este tendrá derecho al reembolso de las cantidades adelantadas, si bien también se prevé la posibilidad de pactar la sustitución del viaje contratado por otro equivalente.

En la práctica ello se traduce en que el consumidor podrá dirigirse al minorista y exigirle el reembolso de las cantidades abonadas en el plazo máximo de 30 días (art. 76 TRLGCDU). En el caso de que el mayorista no reintegre tales cantidades, el minorista deberá asumir esa responsabilidad, pudiendo luego repercutirlas al mayorista.

Esta previsión legal no puede contravenirse ni por acuerdo entre las partes. En efecto, como reconoce la Sentencia de la Audiencia Provincial de Madrid de 4 de octubre de 2016, la regulación legal del desistimiento del consumidor respecto al viaje combinado, "consagra un régimen jurídico exorbitante en beneficio del consumidor que tiene un carácter imperativo, deviniendo radicalmente nula cualquier cláusula contractual, aunque hubiere sido expresamente aceptada por el consumidor, que rebaje al nivel de protección del consumidor recogido en el Ley, la cual habrá de tenerse por no puesta y estarse a la regulación legal".

Sin embargo, esta obligación de indemnizar se excepciona para los casos en los que la cancelación del viaje se deba a motivos de fuerza mayor, o a que el número de personas inscritas sea menor al exigido (art. 159.3). En relación con la fuerza mayor, la Sentencia de la Audiencia Provincial de Madrid de 28 de diciembre de 2012, apelando al art. 11 de la antigua Ley de Viajes Combinados, conjuntamente con el art. 1105 del Código Civil, la define como "aquellos supuestos en que aunque pudieran preverse fueran inevitables", diferenciada del caso fortuito, que son "aquellos casos en que habiendo podido preverse fueran evitables".

La nueva Directiva europea incorpora en su Considerando 31 una relación de circunstancias que han de considerarse casos de fuerza mayor, si bien es claro que no se trata de un numerus clausus: "Tales circunstancias pueden ser, por ejemplo, una guerra u otros problemas graves de seguridad como el terrorismo, riesgos importantes para la salud humana como el brote de una enfermedad grave en el lugar de destino, o catástrofes naturales como inundaciones o terremotos, o condiciones meteorológicas que hagan imposible desplazarse con seguridad al lugar de destino según lo convenido en el contrato de viaje combinado".

En cuanto a la posibilidad de cancelación del viaje por no alcanzar el número mínimo exigido, el art. 159.4 TRLGDCU impone que con anterioridad se haya informado al cliente de 
dicha posibilidad, así como que se le comunique antes de la fecha límite fijada a tal fín en el contrato, que, en ningún caso podrá ser inferior a los diez días anteriores a la fecha prevista para la salida.

En caso de que el organizador suspenda el viaje por no llegar al número mínimo de participantes en el viaje, habrá de responder por dicho incumplimiento, tal y como declara la Sentencia de la Audiencia Provincial de Madrid de 10 de octubre de 2012, no sólo con la devolución de las cantidades adelantadas o la oferta de un viaje alternativo, sino que si lo hace por debajo de los plazos previstos en la norma, deberá indemnizar en los términos previstos en la norma, entendiendo asimismo que "cabe extraer que contraída la indemnización al mínimo contemplado, ninguna prueba precisa en cuanto a daños perjuicios, no siendo posible otra interpretación desde la expresión referido, si bien, obviamente, ese mínimo puede superarse cuando se acrediten perjuicios en cuantía superior a las que de forma concreta el precepto refiere".

Correlativamente, al viajero le asiste el derecho de desistimiento, en cuya virtud, la agencia estará obligada a reembolsarle las cantidades que este haya anticipado, de las que podrá deducir ciertas cantidades, que varían en función de los días de antelación con los que le haya sido comunicada la cancelación. En concreto, estas cantidades ascienden al 5\% del importe total del viaje, si se comunicó con más de diez días de antelación, el 15\% entre los días tres y diez, o el 25\%, si se desiste menos de 48 horas antes de la salida. Si el consumidor se limitase a no presentarse a la salida del viaje, estará obligado al pago del viaje, salvo pacto en contrario (art. 160 TRLGDCU).

También se incluyen entre las cantidades a deducir los gastos de anulación de los billetes de transporte -barco, ferrocarril, avión...-, que en ocasiones pueden suponer una porción elevada del total de gastos del viaje, como es el caso abordado por la Audiencia Provincial de Sevilla de 8 de noviembre de 2011, en el que la cancelación de unos billetes de avión a Australia supuso el reembolso de casi 60.000 euros a la agencia. No obstante, es bien cierto que habitualmente, las agencias ponen a disposición de quienes con ellas contratan diversos seguros que cubren la eventualidad del desistimiento del viaje para los viajeros.

No obstante, el abono de estas cantidades en concepto de indemnización no corresponderán si concurriese un caso de fuerza mayor. Tal es el caso abordado en la Sentencia de la Audiencia Provincial de Madrid de 4 de octubre de 2016, en el que, tras enumerar algunas de las causas de fuerza mayor más habituales -accidente o enfermedad grave del propio consumidor o de familiares cercanos, fallecimiento súbito de un familiar y catástrofes naturales (terremotos, incendios, inundaciones...)-, entendió que una dolencia médica grave debe ser encuadrada en este mismo supuesto de fuerza mayor, por imprevisible, pese a que el historial médico de la persona manifestase que había padecido la misma dolencia -un desprendimiento de retina- en varias ocasiones.

Adicionalmente, analiza cuál debe ser el momento en el que se debe tener por efectuado el desistimiento, decantándose por aquel en el que el consumidor emite su declaración de voluntad con destino al organizador o detallista, por entender que resulta de aplicación lo dispuesto en el art. 71.4 TRLGDCU, en el que se dice que: "Para determinar la observancia del plazo para desistir se tendrá en cuenta la fecha de expedición de la declaración de desistimiento". 


\subsection{Cálculo de la indemnización. La concurrencia de daños morales}

En todas las situaciones expuestas se genera un daño al viajero, que debe ser indemnizado. Sin embargo, la cuestión estriba en determinar cómo se calcula el quantum indemnizatorio. En la nueva Directiva $n^{\circ} 2015 / 2032$ se prevé que el resarcimiento de los daños, que resulten del incumplimiento o de la mala ejecución de las prestaciones incluidas en el viaje combinado, quedará limitado con arreglo a lo previsto en los convenios internacionales que regulen específicamente dichas prestaciones (art. 14.4 y .5), como más adelante se analizará.

En cuanto a la frustración de las expectativas generadas cuando se está ante un incumplimiento parcial, y no total, del contrato, la jurisprudencia se ha inclinado mayoritariamente por no indemnizar al viajero en la cuantía total abonada, sino que se procede a evaluar el servicio efectivamente recibido, comparando este cumplimiento parcialmente defectuoso con el contratado, para la determinación de la cuantía de la indemnización.

Así, la Sentencia de la Audiencia Provincial de Madrid de 10 de febrero de 2017 moduló la indemnización que había de abonar un turoperador a un viajero, al tener en cuenta que, pese a que existió una negligencia, consistente en servir un pastel con gluten a quien presenta intolerancia al mismo, "en ningún momento se desprende que los viajeros vieran interrumpido su crucero, tuvieran que desembarcar, o adoptar otra medida urgente que les impidiera seguir disfrutando del viaje, fuera de la incertidumbre y preocupación por el consumo por parte de su hijo de un producto con gluten".

Pero no siempre la modulación lleva a reducir el quantum indemnizatorio. Por ejemplo, la Sentencia de la Audiencia Provincial de Sevilla de 5 de abril de 2004, en un caso de cancelación de vuelo a consecuencia de una huelga de controladores, entendió que, si bien la suspensión de un vuelo por causas ajenas a los organizadores y detallistas del viaje combinado se podría incardinar en alguna de las causas de exoneración de responsabilidad previstas,la no prestación de la necesaria asistencia al consumidor que se encuentra afectado por la incidencia, "haciendo todo lo posible porque se supere de algún modo la situación creada, proporcionando información, otro vuelo lo más próximo posible, dando alojamiento si fuere necesario, etc. (...)", hace surgir la responsabilidad del organizador del viaje.

Sin embargo, la opción indemnizatoria no es la única prevista en la actual regulación. En efecto, el art. 14 de la Directiva indica que debe reconocerse al viajero el derecho a una reducción del precio adecuada por cualquier período durante el cual haya habido falta de conformidad con los términos pactados, a menos que el organizador demuestre que la falta de conformidad es imputable al propio consumidor. Asimismo, cuando "una proporción significativa de los servicios de viaje no pueda prestarse según lo convenido en el contrato de viaje combinado", si la oferta del organizador representa la realización de un viaje combinado de menor calidad que la especificada en el contrato de viaje combinado, el organizador deberá efectuar una reducción adecuada del precio.

En cuanto a la valoración de los daños materiales sufridos por los viajeros, su cómputo resulta relativamente sencillo, por cuanto puede realizarse un juicio de razonabilidad bastante aproximado teniendo en cuenta las características del viaje, el coste del mismo, y el objetivo con el que se va a desarrollar.

Estos criterios se emplean, entre otras muchas, en la Sentencia de la Audiencia Provincial de Las Palmas de Gran Canaria de 15 de septiembre de 2016, en el que se tiene en 
cuenta para la valoración de la indemnización la situación de tres pasajeros cuyo destino final era Singapur, donde llegaron "sin maletas, tras un larguísimo viaje, en un país extranjero, con necesidad de acudir a reuniones de negocios correctamente vestidos, y sin tiempo material", o la Sentencia de la Audiencia Provincial de Baleares de 5 de abril de 2016, que para el caso del extravío del equipaje de una familia que iba a realizar un crucero tomaba en consideración todo un conjunto de criterios ${ }^{29}$.

En cuanto a la valoración de los daños personales sufridos por los viajeros en el seno de un viaje combinado, la Sentencia del Tribunal Supremo de 8 de abril de 2016 expone que la jurisprudencia ha establecido también sin fisuras la posibilidad de utilizar las reglas del Baremo $^{30}$ como criterios orientadores, no vinculantes, para cuantificar las indemnizaciones por los perjuicios causados a las personas como consecuencia del daño corporal ocasionado en sectores de actividad distintos de la circulación de vehículos de motor, si bien como valor orientativo (entre muchas, las Sentencias del Tribunal Supremo de 30 de noviembre de 2011, de 18 de junio de 2013, o de 27 de mayo de 2015).

Debe abordarse a continuación la posibilidad de incorporar a los citados daños morales en las indemnizaciones, así como su valoración ante un cumplimiento defectuoso por parte del organizador, el minorista o cualquiera de los prestadores de los servicios contratados. La principal razón para la defensa de su inclusión se encuentra en el hecho de que, por su específica naturaleza, se trata de contratos cuya prestación principal se dirige a proporcionar bienestar, placer o tranquilidad al acreedor; en definitiva, satisfacciones de carácter inmaterial $^{31}$.

Para la definición del daño moral en el ámbito de la jurisprudencia europea, como punto de partida habremos de emplear la Sentencia del Tribunal de Justicia de la UE de 12 de marzo de 2002 (Asunto C-168/00, Simone Leitner), que en referencia a la anterior Directiva Europea 90/314/CEE, aclaró que procede incluir en la indemnización también los daños morales, en particular, en caso de las vacaciones malogradas. En este mismo sentido se manifiesta la nueva Directiva europea, cuyo Considerando 34 establece que la indemnización debe cubrir también los perjuicios morales, en particular la indemnización por la pérdida de disfrute del viaje o vacación.

En cuanto a su alcance en la actividad turística en España, se encuentra muy claramente delimitada en la Sentencia del Tribunal Supremo de 22 de febrero de 2001. Esta Sentencia afirma que el daño moral "Se sustantiviza para referirlo a dolor inferido,

\footnotetext{
${ }^{29}$ En concreto, la edad de los consumidores, las pertenencias básicas en la maleta extraviada, su valor respectivo, la presencia de enseres domésticos, así como la imposibilidad asociada de asistir a cenas y fiestas organizadas, con el resto de la familia, a quienes igualmente privaron, la falta de ropa desde inicio al fin del crucero, el deficiente trato recibido, la casi absoluta pérdida de disfrute del crucero, el tratarse de un viaje de descanso y placer, el número de personas que, por familiares directos, viajaban juntos, la afección de la incidencia a todos ellos directa o indirectamente, el coste total del viaje y el extravío de la maleta desde el primer día.

${ }^{30}$ Este Baremo es el que en la actualidad se encuentra recogido en la Ley 35/2015, de 22 de septiembre, de reforma del sistema para la valoración de los daños y perjuicios causados a las personas en accidentes de circulación (BOE $n^{\circ} 228$, de 23 de septiembre de 2015), así como en Resolución de 5 de marzo de 2014, de la Dirección General de Seguros y Fondos de Pensiones, por la que se publican las cuantías de las indemnizaciones por muerte, lesiones permanentes e incapacidad temporal que resultarán de aplicar durante 2014 el sistema para valoración de los daños y perjuicios causados a las personas en accidentes de circulación (BOE $\mathrm{n}^{\circ}$ 64, de 15 de marzo de 2014)

31 SOLÉ FELIU, J., "El daño moral por infracción contractual: principios, modelos y derecho español”, en InDret, Revista para el análisis del Derecho, nº 1, 2009, pág. 21.
} 
sufrimiento psíquico o espiritual, tristeza, angustia, trastorno de ansiedad, desazón, impacto emocional, zozobra o inquietud que afecta a la persona que lo padece, o, en general, el dolor $y$ angustia de las personas perjudicadas por el actuar injusto, abusivo o ilegal de otro", (...)el viajero que contrata uno de estos viajes, al ser incumplido, imposibilitándole por ejemplo la realización de un visita a un monumento al que no volverá, so pena de grave quebranto económico, padece esa ansiedad, desazón, impacto o sufrimiento, que constituye la esencia del daño moral, que como tal no atiende a la reintegración de un patrimonio, sino que va dirigida de modo principal a proporcionar en la medida de lo humanamente posible una satisfacción como compensación al sufrimiento que se ha causado (...)”.

En términos empleados por la Sentencia de la Audiencia Provincial de Cantabria de 26 de enero de 2011, el daño moral por la frustración del plan vacacional proyectado, es "indudablemente generador de un malestar psíquico, un padecimiento que conforme a normas comunes de experiencia no puede ser negado y que viene siendo reconocido de ordinario por los tribunales en estos casos", como reconocieron, entre otras muchas, la Sentencia de la Audiencia Provincial de Madrid de 19 de enero de 2010 o de la Audiencia Provincial de Palencia de 17 de junio de 2010, para aquellos casos en los que la situación excede de la mera incomodidad.

Por su parte, la Sentencia del Tribunal Supremo de fecha 8 de abril de 2016 indica que, si bien en ninguno de los apartados del art. 162 TRLGDCU se especifique concretamente la indemnización de los daños morales, debe entenderse que sí corresponde indemnizarlos, puesto que "tanto jurisprudencial como doctrinalmente se considera que el apartado $2^{\circ}$ del artículo $162 \mathrm{LCU}$, aunque no referencia expresamente los daños morales, se conceptúan dentro del concepto de daños".

Del análisis de la jurisprudencia se desprende que para cuantificar el daño moral sufrido y su concreta indemnización, los tribunales tienen en cuenta dos datos: el importe total del precio del viaje y la posibilidad de disfrute de los actores en alguna fase del viaje ${ }^{32}$. Por norma general, el objeto de las reclamaciones y demandas de los viajeros suele ser la frustración de las expectativas respecto al itinerario y los servicios de ocio contratados, no desarrollados en los términos pactados $\mathrm{y}$, en menor medida, la existencia de unos daños materiales efectivos.

En España, tal y como acertadamente expone la Sentencia de la Audiencia Provincial de Valladolid de 2 de noviembre de 2011, "la valoración del daño moral no puede obtenerse de una prueba objetiva, y su relatividad e imprecisión impide una exigencia judicial respecto de su exigencia y traducción económica o patrimonial y exige la utilización de un prudente criterio, debiendo resolverse con pragmatismo y aproximación".

Por ello, la Sentencia de la Audiencia Provincial de Madrid, de 15 de diciembre de 2006, consideró que existe un daño moral indemnizable cuando en un viaje combinado se produce un incumplimiento, siempre que se consiga acreditar la existencia de situaciones que han alcanzado un grado de incomodidad, penalidad o perturbación suficiente. A este respecto, la Audiencia Provincial de Cantabria, en su Sentencia de 20 de enero de 2015, evaluó la existencia de daños morales, modulando su cuantía, teniendo en cuenta "la clase de

32 LUQUE JIMÉNEZ, M C., "Vacaciones frustradas: Análisis del incumplimiento y responsabilidad", en Nuevas perspectivas del turismo para la próxima década: III Jornadas de Investigación en Turismo, por JIMÉNEZ CABALLERO, J.L. y DE FUENTES RUIZ, P. (Coord.), Ed.

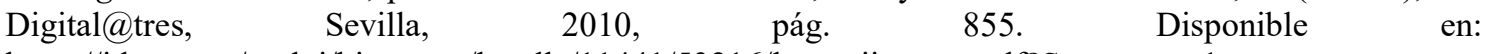
https://idus.us.es/xmlui/bitstream/handle/11441/53216/luque-jimenez.pdf?Sequence= 1 . 
enfermedad que padecieron los actores (salmonelosis), y que dichas molestias, al producirse en el marco de un viaje turístico, privaron a los actores de una parte importante de placer y descanso que son propios de esos periodos".

A este respecto, existe una amplia jurisprudencia sobre la especial valoración que merecen los incumplimientos durante una luna de miel, por la causa que expone la Sentencia de la Audiencia Provincial de Madrid de 22 de julio de 2009:"la ocasión especial del viaje de novios, de tanta importancia en la vida de la pareja ha dejado de ser un recuerdo feliz, placentero e inolvidable, pasa a ser un recuerdo con cierto sabor amargo por las incomodidades e incidencias del viaje. Hay evidente daño moral para los actores a quienes se le agria el viaje, y se les perjudica el ocio", siendo "un viaje único en la vida", como afirmó la Sentencia de la Audiencia Provincial de Guipúzcoa de 11 de septiembre de 2008, en un criterio que sigue, entre otras muchas, la Sentencia de la Audiencia Provincial de Sevilla de 7 de abril de 2016.

Ello ameritó que, por ejemplo, la Sentencia de la Audiencia Provincial de Las Palmas de 16 de septiembre de 2005 decidiese incrementar en un 25 por ciento el importe de la indemnización "en atención a la circunstancia de tratarse del viaje de novios de los apelantes". Por supuesto, dicha especial consideración se traslada a las segundas nupcias y las subsiguientes, como afirmaba la Sentencia de la Audiencia Provincial de Alicante de 13 de junio de 2005, "algunos de los criterios que se aducen por la recurrente para fundar la inexistencia del daño («que el viaje no era irrepetible, ambos estaban divorciados y habían pasado ya por la experiencia de luna de miel u ocasiones similares ...»), son, cuanto menos, descorteses, inadecuados por su falta de elegancia e impropios, por contener tintes claramente discriminatorios respecto a esas personas (...)".

Finalmente, y en cuanto al tiempo de que dispone el viajero perjudicado para ejercitar las acciones judiciales pertinentes, el apartado 6 del art. 14 de la Directiva señala un plazo de prescripción para reclamar de, al menos, dos años. En España, el art. 164 TRLGDCU establece este mismo plazo de prescripción de dos años para las acciones derivadas de los derechos reconocidos en el libro IV (en el que se regula el contrato de viaje combinado), lo que incluye no sólo las acciones del consumidor contra el organizador o detallista, sino también las que éstos pudieran tener contra aquél. Dicha acción puede interponerse ante los Tribunales ordinarios, o bien ante las Juntas Arbitrales de Consumo, en caso de que con carácter previo ambas partes hayan acordado voluntariamente someterse al pronunciamiento de la Junta.

En cuanto al dies a quo para el plazo de prescripción, las Sentencias de la Audiencia Provincial de Madrid de 14 de noviembre de 2013 y de 13 de mayo de 2016 entendieron que en el caso de daños personales sufridos por los viajeros, no debe tenerse en cuenta como fecha inicial del cómputo la del alta en la enfermedad, sino la de la determinación del efecto de invalidez de las secuelas, es decir, el momento en que queda determinada la incapacidad o los defectos permanentes originados, "pues hasta que no se conoce su alcance no puede reclamarse con base en ellas, ya que es en ese momento cuando el perjudicado tiene un conocimiento preciso de la entidad de los perjuicios". Esta doctrina obedece, en atención al principio de indemnidad, a la necesidad de preservar el derecho del perjudicado a ser íntegramente resarcido en situaciones en que no ha podido hasta entonces conocer en su totalidad el alcance de su daño, por causas en modo alguno imputables a su persona o comportamiento. 
Al mismo tiempo, se entiende que la presentación de diligencias interrumpe la prescripción, como afirman la Sentencia de la Audiencia Provincial de Madrid de 1 de diciembre de 2014, así como las citadas Sentencias de 14 de noviembre de 2013 y de 13 de mayo de 2016, de la Audiencia Provincial de Madrid.

\subsection{Respuesta frente a la insolvencia del organizador}

Existe una última cuestión a evaluar respecto a los daños ocasionados a los viajeros, que es el correspondiente a las situaciones de insolvencia de la agencia de viajes o el turoperador, y qué medidas se han arbitrado en la actual legislación para su protección. Para ello, hay que comenzar reconociendo los problemas que hasta muy recientes fechas encontraban los viajeros que sufrían este tipo de incidencias para la reparación de sus daños, e incluso para su repatriación cuando alguno de los operadores turísticos incurría en una situación de quiebra o de insolvencia ${ }^{33}$.

Es por ello que la nueva Directiva UE supone un gran avance para el consumidor europeo, al exigirá los Estados miembros en su art. 17 que elaboren una normativa capaz de garantizar que los "organizadores" que operen en su territorio constituyan una garantía frente a la insolvencia, que permita el reembolso íntegro de la cantidad desembolsada por el viajero, si los servicios contratados no se hubiesen ejecutado a causa de dicha insolvencia del organizador. También prevé la norma el establecimiento de la correspondiente garantía para la repatriación y financiación del alojamiento previo, en caso de que el transporte de pasajeros estuviese incluido en el contrato de viaje combinado.

La protección a los viajeros se extiende a los seguros de repatriación y reembolso de los importes desembolsados suscritos por el turoperador, obligando a las compañías aseguradoras a abonar las cantidades aseguradas incluso en aquellos casos en que la no realización del viaje se debe a una insolvencia cuyo origen se encuentra en un comportamiento fraudulento o irregular por parte del organizador del viaje, o a la ocurrencia de hechos excepcionales o imprevisibles, tal y como aseveró el Tribunal de Justicia de la Unión Europea en su Sentencia de 16 de febrero de 2012 (Asunto C-134/11. Jürgen BlödelPawlik y Hanse Merkur Reiseversicherung).

En España ya existe una previsión de protección a los consumidores frente a la insolvencia, incorporada a la legislación nacional. En efecto, el art. 163 TRLGDCU fue modificado por laLey $15 / 2015$, de 2 de julio ${ }^{34}$, pasando a incorporar la obligación para los organizadores y detallistas de "constituir y mantener de manera permanente una garantía en los términos que determine la Administración turística competente, para responder con carácter general del cumplimiento de las obligaciones derivadas de la prestación de sus servicios frente a los contratantes de un viaje combinado" $\mathrm{y}$, especialmente, en caso de insolvencia, del reembolso efectivo de todos los pagos realizados por los viajeros en la medida en que no se hayan realizado los servicios correspondientes y, en el caso de que se incluya el transporte, de la repatriación efectiva de los mismos, que debe efectuarse en todo caso.

\footnotetext{
${ }^{33}$ Para un análisis en profundidad de la actual regulación en esta materia, resulta muy interesante el texto elaborado para el CESCO por MARTÍNEZ ESPÍN, P., La reforma del artículo 163 TRLGDCU por la Ley de Jurisdicción Voluntaria. Disponible en: http://blog.uclm.es/cesco/files/2015/08/La-reformadel-art\%C3\%ADculo-163-TRLGDCU-por-la-Ley-de-Jurisdicci\%C3\%B3n-Voluntaria.pdf.

${ }^{34}$ Ley 15/2015, de 2 de julio, de la Jurisdicción Voluntaria. BOE n ${ }^{\mathrm{o}} 158$, de 3 de julio de 2015.
} 
Dicho fondo deberá ser de fácil acceso para el viajero, sin trámites excesivos, ni demora indebida y de forma gratuita (art. 163.2). Adicionalmente, en caso de ejecutarse la garantía, deberá reponerse en el plazo de quince días, hasta cubrir nuevamente la totalidad inicial de la misma (art. 163.3).

\subsection{Casos de exclusión de responsabilidad de los organizadores y las agencias}

El régimen general de responsabilidad en los viajes combinados debe completarse atendiendo a aquellas situaciones en las que tanto turoperadores como agencias de viajes no han de asumir responsabilidad alguna frente a los consumidores y usuarios por los sucesos acaecidos a lo largo de su itinerario. Como es evidente, no toda incidencia sufrida por un viajero es imputable a quienes organizan y prestan los servicios que éste emplea, por lo que se hace necesario, en primer lugar, determinar cuáles son estas situaciones en las que cesa la responsabilidad de organizadores y detallistas de viajes combinados.

En este caso, la propia Directiva de la Unión Europea ha enumerado en su art. 14.3 una serie de situaciones de exclusión de responsabilidad, que puede resumirse en la concurrencia de alguna de las siguientes circunstancias:

En primer lugar, que los defectos observados en la ejecución del contrato sean imputables al viajero. Sin embargo, a este respecto debe tenerse en cuenta la previsión general del art. 162 TRLGDCU, que reconoce al consumidor y usuario como norma de carácter general, el derecho a ser indemnizado por los daños y perjuicios sufridos por el consumo de bienes o la utilización de productos o servicios, salvo que los defectos observados en la ejecución del contrato sean imputables al él. A tenor de la Sentencia del Tribunal Supremo de 23 de julio de 2001, esta norma establece un principio de inversión de la carga de la prueba, de forma que es el productor o suministrador de los productos o servicios quien ha de evidenciar que el origen de los daños y perjuicios se encuentra en la conducta culposa del usuario o de las personas por las que debe responder.

Un caso claro de culpa exclusiva del viajero se da cuando no puede efectuar su itinerario por ser expulsado de un hotel a causa de su comportamiento inadecuado. Este supuesto se abordó en la Sentencia de la Audiencia Provincial de Madrid de 17 de enero de 2012, en el que a un grupo de estudiantes a los que se cambió el hotel que inicialmente habían contratado se les denegó cualquier tipo de compensación, al entender el juzgador que la modificación se debió a la expulsión del grupo del primero de los hoteles por no cumplir las normas de comportamiento del establecimiento, actuando con un comportamiento inadmisible para los demás huéspedes.

Otra causa habitual por la que concurre la culpa exclusiva del viajero es la caducidad de la documentación que le es exigida por las autoridades para el viaje. Tal caso fue atendido por las Sentencias de la Audiencia Provincial de Navarra en su Sentencia de 29 de julio de 1999 o de la Audiencia Provincial de Barcelona de 1 de marzo de 2001, en las que sendos pasajeros no pudieron tomar los vuelos con los que iniciaban sus viajes combinados por llevar sus DNI caducados.

Por su parte, la Sentencia de la Audiencia Provincial de las Islas Baleares de 11 de abril de 2011 rechazó la responsabilidad de la agencia de viajes por no haber proporcionado información al viajero respecto al visado que debía obtener para entrar en la India porque éste ya había viajado con anterioridad a dicho país, y debía conocer las obligaciones documentales 
exigidas por las autoridades de aquel país. Asimismo, la Sentencia de la Audiencia Provincial de Valladolid de 26 de julio de 2005 no estimó la solicitud de indemnización de un viajero a quien se le impidió el acceso a Estados Unidos por tratarse de un periodista que acudía a realizar un reportaje, entendiendo el juzgador que al tratarse de una actividad ajena a agencia, que requería una solicitud específica y la entrevista personal al interesado, escapaba al ámbito de gestión exigible a la agencia de viajes.

Otra posibilidad es que el defecto en la prestación de los servicios se deba a un tercero ajeno al suministro de las prestaciones previstas en el contrato, por una causa de carácter imprevisible o insuperable para el turoperador, la agencia y los prestadores de servicios.

Un caso puede ser el de las huelgas de controladores aéreos. Sin embargo, se mantendrá la responsabilidad de los organizadores y detallistas del viaje combinado "si no prestan la necesaria asistencia al consumidor que se encuentra afectado por la cancelación del vuelo, haciendo todo lo posible porque se supere de algún modo la situación creada, proporcionando información, otro vuelo lo más próximo posible, dando alojamiento si fuera necesario, etc..., actuaciones que corresponde acreditar a quien debia prestarla, porque se trata de probar el cumplimiento de sus obligaciones", como afirma la Sentencia de la Audiencia Provincial de Sevilla de 5 de abril de 2004.

Por su parte, la legislación española prevé también unas causas de exclusión de la responsabilidad de los organizadores y detallistas de viajes combinados. En concreto, el art.162.2.c) TRLGDCU establece como causa de exención de responsabilidad "Que los defectos aludidos se deban a motivos de fuerza mayor, entendiendo por tales aquellas circunstancias ajenas a quien las invoca, anormales e imprevisibles cuyas consecuencias no habrían podido evitarse, a pesar de haber actuado con la diligencia debida".

De ello se desprende que para que pueda estimarse la fuerza mayor como causa de exoneración de responsabilidad habrán de concurrir una serie de requisitos, enumerados en la Sentencia de la Audiencia Provincial de La Coruña de 17 de diciembre de 2007: (i) Estar ante un hecho o acontecimiento independiente de la voluntad del agente causante y, por tanto, no imputable a él. Ha de tratarse de una fuerza superior a todo control y previsión y que excluya toda intervención de culpa; (ii) El acontecimiento debe ser imprevisto e imprevisible, dentro de la normal previsión que las circunstancias exigen en el caso de que se trate; (iii) En el nexo de causalidad entre el acontecimiento y el evento dañoso no debe haber intervenido la actividad, dolosa o culposa, del agente; y (iv) Debe probarse el evento de una forma cumplida y satisfactoria.

Esto se debe tener en cuenta en referencia a la probabilidad del acaecimiento de determinados fenómenos naturales -como pueden ser los huracanes- en ciertas épocas del año, que por su reiteración cíclica puedan resultar previsibles para los organizadores del viaje, a quienes les alcanza la obligación de informar a sus potenciales clientes de dicho extremo, a la luz del art. 152 TRLGDCU.

Como afirma la Sentencia de la Audiencia Provincial de Barcelona de 23 de julio de 2015, "Existe una amplio cuerpo de doctrina jurisprudencial en las Audiencias Provinciales que, teniendo en cuenta la relativa frecuencia con la que dichos acontecimientos atmosféricos se producen en el Caribe en una determinada época del año, hasta el punto de que en los propios folletos del viaje se informa al consumidor de dicho riesgo, viene considerando que el riesgo de Huracanes no puede considerarse un evento anormal e imprevisible que permita calificarlo de fuerza mayor, sino que se trata de un riesgo inherente a este tipo de viajes que debe asumir la empresa organizadora, sobre todo cuando se tiene identificada su formación o 
alguno de los fenómenos meteorológicos que la preceden como pueden ser la 'depresión tropical' y la 'tormenta tropical', por lo que en tales supuestos los viajeros deben ser oportunamente informados de este riesgo por si les interesa una modificación de los términos del contrato o incluso el desistimiento del mismo". Esta obligatoriedad también fue defendida por la Sentencia de la Audiencia Provincial de Santa Cruz de Tenerife de 13 de octubre de 2008.

Sin embargo, la Audiencia Provincial de Vitoria moduló en su Sentencia de 19 de septiembre de 2008 la responsabilidad de la mayorista, que fue minorada por entender que los viajeros "sabían que en esas fechas la zona elegida tiene riesgos de fuertes tormentas y huracanes, internet mantiene informado a cualquier persona del clima mundial, pese a ello eligieron esa zona para disfrutar de sus vacaciones". Compartiendo el argumento de la Sentencia, parece razonable entender que en un mundo en el que la información global fluye, y desde luego España no escapa a esa sociedad de la información, ningún viajero puede argumentar que desconoce por completo la situación del punto de destino de su itinerario.

Éste mismo régimen se aplicó por la Audiencia Provincial de Valladolid en su Sentencia de 12 de febrero de 2009, ante un viaje combinado que tuvo que ser cancelado a causa de una amenaza terrorista que provocó el cierre del aeropuerto de Heathrow en Londres. El juzgador entendió que no se estaba ante un supuesto de responsabilidad por incumplimiento contractual que pudiera imputarse al minorista y organizador de viaje, sino ante una anulación o cancelación inicial del viaje contratado por acaecer una causa de fuerza mayor ajena a la voluntad de todas las partes.

Igualmente, y en función de cuál es el objetivo final del viaje, podemos encontrar situaciones en los que desaparece la responsabilidad frente al consumidor por los daños que éste sufre en un viaje combinado. Esto se da en el caso de los viajes combinados efectuados con la finalidad de efectuar actividades de peligro extremo, o deportes de riesgo. Si ya la realización de una actividad deportiva supone la asunción de riesgos, materializados en la forma de lesiones, la posibilidad de daños se incrementa con la práctica de los llamados deportes de riesgo, uno de cuyos principales atractivos reside, precisamente, en la superación del peligro que conllevan o de las condiciones extremas en que se practican.

Evidentemente, esta premisa debe ser tenida en cuenta a la hora de evaluar las circunstancias que rodean al incidente sufrido por un viajero en el desarrollo de una de estas actividades de riesgo, si bien habrá que tener siempre presente que ello no implica que el organizador o la agencia no respondan por las incidencias que no se relacionan con el riesgo aceptado por el viajero en relación con dicha actividad. En suma, la responsabilidad del organizador o explotador aplica cuando se detecta alguna irregularidad culpable en la organización o el funcionamiento, pero debe excluirse en caso de lesiones derivadas de su funcionamiento normal.

En definitiva, valga el acertado argumento de la Sentencia de la Audiencia Provincial de Barcelona de 15 de noviembre de 2016: "En lo que respecta al régimen de responsabilidad de las empresas que organizan actividades deportivas cabe afirmar que, en la medida en que el daño causado pueda considerarse asumido por el practicante de esa actividad, la responsabilidad quedará excluida. Sin embargo, en los supuestos en que el daño no deba reputarse asumido por el deportista ya sea por la concurrencia de circunstancias que han determinado una agravación del riesgo asumido, ya por haber incurrido la empresa organizadora en falta de diligencia, las responsabilidades consecuentes deberán imputarse a la persona $u$ entidad responsable". 
En todo caso, el hecho de que no se genere una responsabilidad frente al viajero no significa que este quede absolutamente desamparado. Por el contrario, pese a no existir responsabilidad alguna para el organizador y el detallista, éstos quedarán obligados a reembolsar al viajero los gastos abonados por este, además de a prestar la necesaria asistencia al consumidor y usuario que se encuentre en dificultades, en los términos que se analizarán más adelante.

\subsection{La incardinación del transporte en el régimen indemnizatorio}

A la regulación del régimen de responsabilidad debe unirse la previsión existente en el art. 14.4 de la Directiva (UE) 2015/2302 de que en las prestaciones del viaje combinado relacionadas con el transporte de los viajeros, habrá de atender a la normativa específica relacionada con el estatuto del pasajero en dicho medio de transporte, debiendo armonizar sus disposiciones con los Convenios internacionales en materia de servicios de viaje y con la legislación de la propia Unión Europea sobre los derechos de los pasajeros.

Como afirma el Considerando 35 de la propia Directiva, el organizador debe poder acogerse la responsabilidad limitada de los prestadores de servicios de viaje establecida en los distintos Convenios internacionales, citando específicamente para el transporte aéreo en el Convenio de Montreal de $1999^{35}$, para el ferrocarril con el Convenio de 1980 (COTIF) ${ }^{36}$, y el Convenio de Atenas de $1974^{37}$ para el transporte por vía marítima.

En este sentido, el art. 14.5 permite compatibilizar las reclamaciones de indemnización o reducción del precio previstos en la Directiva con las propias de las normas europeas que regulan los derechos de los viajeros, como son el Reglamento (CE) $n^{\circ} 261 / 2004^{38}$ para el transporte aéreo, el Reglamento (CE) $n^{\circ} 1371 / 2007^{39}$ para el ferrocarril, el Reglamento (CE) $n^{\circ}$ $392 / 2009^{40}$ para el transporte marítimo de pasajeros y por vías navegables y el Reglamento (UE) $\mathrm{n}^{\mathrm{o}} 1177 / 2010^{41}$ y el Reglamento (UE) $\mathrm{n}^{\mathrm{o}} 181 / 2011^{42}$ para el transporte por carretera en autobús y autocar.

${ }^{35}$ Convenio para la unificación de ciertas reglas para el transporte aéreo internacional, hecho en Montreal el 28 de mayo de 1999. Publicado en el BOE no 122, de 20 de mayo de 2004.

${ }^{36}$ Convenio Internacional relativo a los Transportes Internacionales por Ferrocarril (COTIF), hecho en Berna el 9 de mayo de 1980. Publicado en el BOE nº 16, de 18 de enero de 1986.

${ }^{37}$ Convenio relativo al Transporte de Pasajeros y sus Equipajes por Mar, hecho en Atenas el 13 de diciembre de 1974. Publicado en el BOE n ${ }^{\circ} 108$, de 6 de mayo de 1987.

${ }^{38}$ Reglamento (CE) no 261/2004 del Parlamento Europeo y del Consejo, de 11 de febrero de 2004, por el que se establecen normas comunes sobre compensación y asistencia a los pasajeros aéreos en caso de denegación de embarque y de cancelación o gran retraso de los vuelos, y se deroga el Reglamento (CEE) $n^{\circ}$ 295/91. DOUE no 46, de 17 de febrero de 2004.

${ }^{39}$ Reglamento (CE) no 1371/2007 del Parlamento Europeo y del Consejo, de 23 de octubre de 2007, sobre los derechos y las obligaciones de los viajeros de ferrocarril. DOUE $\mathrm{n}^{\mathrm{o}} 315$, de 3 de diciembre de 2007.

${ }^{40}$ Reglamento (CE) no 392/2009 del Parlamento Europeo y del Consejo de 23 de abril de 2009, sobre la responsabilidad de los transportistas de pasajeros por mar en caso de accidente. DOUE $\mathrm{n}^{\mathrm{o}} 131$, de 28 de mayo de 2009.

${ }^{41}$ Reglamento (UE) no 1177/2010 del Parlamento Europeo y del Consejo, de 24 de noviembre de 2010, sobre los derechos de los pasajeros que viajan por mar y por vías navegables y por el que se modifica el Reglamento (CE) n 2006/2004. DOUE n⿳3 334, de 17 de diciembre de 2010.

${ }^{42}$ Reglamento (UE) $n^{\circ} 181 / 2011$ del Parlamento Europeo y del Consejo, de 16 de febrero de 2011, sobre los derechos de los viajeros de autobús y autocar y por el que se modifica el Reglamento (CE) $n^{\circ} 2006 / 2004$. DOUE $n^{\circ} 55$, de 26 de febrero de 2011. 
Con la finalidad de hacer compatibles ambos regímenes compensatorios, la indemnización o reducción del precio que correspondiese en virtud de la Directiva y la concedida en virtud de dichos reglamentos y convenios internacionales se deberán deducir la una de la otra para evitar el exceso de indemnización.

En este sentido, la Sentencia de la Audiencia Provincial de Madrid de 27 de enero de 2017 entendió que el hecho de que exista responsabilidad solidaria frente al consumidor no supone que la empresa organizadora sea la obligada a satisfacer las indemnizaciones por los retrasos previstos en el Reglamento (CE) $n^{0}$ 261/2004, debiendo discernirse entre esa indemnización, exigible tan sólo a las empresas transportistas aéreas, por un lado, y los perjuicios dimanantes de la cancelación del vuelo reclamables a la empresa organizadora.

Además, para el caso de que por circunstancias inevitables y extraordinarias sea imposible garantizar el retorno a tiempo de los viajeros al lugar de salida, la Directiva impone al organizador asumir el coste del alojamiento necesario de los viajeros durante tres noches por viajero como máximo, a menos que la legislación vigente o futura de la Unión sobre derechos de los pasajeros establezca un período más largo.

\section{DAÑOS NO OCASIONADOS POR UNA EJECUCIÓN DEFICIENTE DEL CONTRATO: ASISTENCIA}

Como se ha visto anteriormente, el mero hecho del surgimiento de un daño para el viajero no supone que surja de forma automática una responsabilidad de carácter objetivo para turoperadores, agencias de viajes o prestadores de servicios. En efecto, en los casos previstos en el art. 14.3 de la Directiva, que ya han sido enunciados, la responsabilidad de éstos cesa, para dar paso a un régimen de mera asistencia al viajero.

Esta asistencia en aquellos casos en los que el viajero se halle en dificultades durante el viaje o vacación, según prevé la norma europea, deberá ser prestada por el organizador, que además deberá actuar sin demora indebida, y prestando una asistencia adecuada, según se prevé en los arts. 13.5, .6 y .7 de la Directiva.

\subsection{El deber de información al viajero}

A la vista de la regulación, el organizador no debe limitarse a proporcionar la asistencia con posterioridad al surgimiento de la situación concreta. El art. 5 de la Directiva europea impone que, con carácter previo al inicio del viaje, remita la información necesaria al viajero, que permita a éste conocer la reacción más adecuada si se produjera alguna incidencia durante el viaje.

Dicha información deberá versar, sobre todo, acerca de la información general sobre los requisitos de pasaporte y visado, incluido el tiempo aproximado para la obtención de visados, e información sobre los trámites sanitarios para el país de destino, pero también deberá abarcar aspectos tales como el nombre, dirección y número de teléfono de la representación del organizador en cada destino, datos relevantes acerca de los servicios sanitarios existentes, los datos de contacto de las autoridades, instituciones y servicios locales existentes y que puedan ayudarle en caso de dificultades, así como de la asistencia consular, 
completando estos datos con diversas ayudas prácticas, relativas a, por ejemplo, las comunicaciones a distancia, o las fórmulas alternativas de viaje.

En todo caso, la Directiva impone la obligación de informar al viajero de quién es el responsable de su viaje combinado, así como a facilitarle un número de teléfono de asistencia permanente al cliente, permitiéndole mantener una vía de comunicación permanente con quien está en mejor disposición de ayudarle a encontrar una solución ante cualquier incidencia que se le pueda producir a lo largo de su itinerario.

Esta obligación previa de los detallistas o, en su caso, los organizadores de viajes combinados de proporcionar información relevante al viajero también se prevé en la regulación nacional. El art. 156 TRLGDCU les impone que faciliten información referente a los horarios y lugares de las escalas y los enlaces, así como la indicación de la categoría del lugar que deberá ocupar el viajero en el medio o medios de transporte que vayan a ser utilizados, el contacto del organizador o detallista en cada destino o, en su defecto, los de los organismos locales que puedan ayudar al consumidor y usuario en caso de dificultades o, en cualquier caso, de un número de teléfono de urgencia o de cualquier otra información que le permita al viajero ponerse en contacto con ellos. A esto debe unirse la previsión general el art. 60 TRLGDCU, que exige proporcionar al consumidor información previa al contrato "relevante y suficiente".

Los tribunales se han manifestado reiteradamente acerca de esta obligación de proporcionar información previa al consumidor. Entre otras muchas, la Sentencia la Audiencia Provincial de Madrid de 12 de marzo de 2010, que entendió que existía un cumplimiento contractual defectuoso por no informar de la obligatoriedad de la obtención de visado a un pasajero ecuatoriano que viajaba desde España a Tailandia, con escala en Italia. El juzgador consideró que "Es evidente que la exigencia de visado en una información relevante para la ejecución del contrato por lo que omisión supone un incumplimiento de la normativa reseñada". Casos idénticos a los abordados por las Sentencias de la Audiencia Provincial de Alicante de 26 de marzo de 2013, de la Audiencia Provincial de Gerona de 27de marzo de 2014, o de la Audiencia Provincial de Baleares de 28 de octubre de 2014.

En palabras de la Audiencia Provincial de Guipúzcoa de 3 de febrero de 2012, "No basta por tanto con menciones genéricas sobre los requisitos necesarios para realizar el viaje contratado y tampoco con la afirmación de que se expuso la necesidad de contener en regla la documentación, siendo evidente que en un viaje como el contratado por los actores dentro de la información que expresamente se les debía transmitir estaba la necesaria mención de (...) las condiciones de pasaportes y visados"

Por último, y con carácter adicional, además de proporcionar información acerca de las incidencias previsibles en su viaje, tanto el art. 5.1.h) de la Directiva europea como el art. 156.3 TRLGDCU impone a las agencias la obligación de informar al viajero de la posibilidad de suscribir un seguro que cubra la asistencia sanitaria, correspondiendo a éste la potestad de elegir si finalmente opta por contratarlo o no. Evidentemente, y con carácter adicional, el viajero podrá suscribir cuantas otras modalidades de seguro considere convenientes -de asistencia sanitaria, de accidentes o de cancelación del viaje, entre otros-.

El viajero, con la suscripción del seguro, genera unas obligaciones no sólo para la compañía aseguradora, sino que alcanzan también a la agencia y el turoperador. En su Sentencia de 29 de mayo de 2002, la Audiencia Provincial de Barcelona consideró que, en un accidente surgido durante un viaje, habiendo suscrito un seguro de asistencia que cubría los gastos de repatriación o traslado al lugar de origen en caso de accidente, enfermedad o 
fallecimiento, y ante el surgimiento de un hecho imprevisto y ajeno a la voluntad del viajero como es un accidente, el viajero dispone de una facultad resolutoria del contrato de viaje combinado de la que puede hacer uso, correspondiendo a la compañía aseguradora la repatriación del viajero asegurado.

\subsection{El deber de asistencia al viajero}

Pese a que el hecho de que el viajero disponga de una información previa relevante y eficaz supone una evidente ayuda, sin embargo, puede resultar insuficiente en situaciones en las que el viajero, por desconocimiento, inexperiencia, o simplemente porque la situación en la que se encuentra inmersa supera a sus posibilidades de actuación-piénsese en contingencias tales como conflictos bélicos, desastres naturales o ataques terroristas-. Ante este tipo de eventualidades, surge para el organizador la obligación de prestar al viajero la imprescindible asistencia que éste necesita.

Así se prevé en la Directiva 2015/2302, que afirma en su Considerando 37 que "Si el viajero se halla en dificultades durante el viaje o vacación, el organizador debe estar obligado a prestar una asistencia adecuada sin demora indebida. Dicha asistencia debe consistir, sobre todo, en proporcionar, en su caso, información sobre aspectos tales como los servicios sanitarios, las autoridades locales y la asistencia consular, así como en ayuda práctica, por ejemplo para las comunicaciones a distancia y las fórmulas alternativas de viaje".

En este sentido, la Directiva europea contiene una previsión concreta, de aplicación en el caso de que al viajero le resulta imposible retornar en los términos pactados, a causa de la concurrencia de alguna circunstancia extraordinaria e inevitable. En tal caso, el art. 13.7 incorpora la previsión de que el organizador asuma el coste de tres noches de alojamiento, a ser posible en un alojamiento de categoría equivalente a la contratada, excepto en el caso de que la regulación europea que resulte de aplicación a los derechos de los pasajeros establezca períodos más largos, en cuyo caso serán estos los que resulten aplicables.

Por otra parte, en la norma se prevé un período superior de asistencia para los casos que afectena personas con movilidad reducida y sus acompañantes, a mujeres embarazadas o menores no acompañados, así como a personas con necesidad de asistencia médica específica.(art. 13.8).

Adicionalmente, el art. 16 de la nueva Directiva europea prevé la posibilidad de que el organizador del viaje cobre un recargo razonable -que no podrá superar sus propios costes reales- por la prestación de asistencia en los casos en que la situación se originó por negligencia o dolo del viajero. Esto lleva a alcanzar una doble conclusión: (i) Por un lado, que a diferencia de lo establecido en la anterior Directiva 90/314/CEE, la obligación de prestar asistencia también alcanza al organizador; (ii) Por otro lado, que no podrá cobrar dicho recargo cuando la situación sea imputable a un tercero o a un suceso imprevisible e inevitable.

Por supuesto, en caso de que las incidencias se produjesen antes del comienzo de su itinerario, el viajero dispone de la posibilidad de rescindir el contrato sin hacer frente a ningún tipo de penalización. De esta forma, de existircircunstancias inevitables y extraordinarias en el lugar de destino o en las inmediaciones que afectasen de forma significativa a la ejecución del viaje combinado o al transporte de pasajeros al lugar de destino, al pasajero le amparará su derecho a un reembolso completo, aunque no a una indemnización adicional. 
La legislación española también prevé un régimen específico de asistencia a los viajeros, cuando éstos se encuentren inmersos en una situación que así lo requiera-"se encuentre en dificultades", según se enuncia en el último párrafo del art. 162.2-. Sin embargo la norma no incluye entre las situaciones que requieren asistencia las generadas por el propio consumidor.

Sin duda, se trata de un precepto que deberá ser modificado, puesto que su contenido contradice la regulación europea, ya que el art. 16 de la Directiva europea no distingue entre los motivos por los que el viajero requiera asistencia, limitándose a permitir al organizador facturar "un recargo razonable", que no supere los costes reales en los que haya incurrido por su asistencia, si la dificultad se ha originado intencionadamente o por negligencia del viajero.

Como se puede imaginar, el enorme caudal de situaciones que pueden surgir a lo largo de los viajes combinados, a su vez tan variados en cuanto a su contenido y riesgos implícitos $\mathrm{y}$, en algunos casos explícitos ${ }^{43}$-, que debe acudirse a un análisis de los incumplimientos relacionados con la falta de asistencia ante la concurrencia de las principales eventualidades que suelen darse en el curso de un viaje combinado, con la finalidad de extraer de ellas unos criterios generales, legales y jurisprudenciales.

Una de las incidencias más habituales para los viajeros es el de la necesidad de modificar o suspender su itinerario por causas médicas. En este caso, como acertadamente considera la Sentencia de la Audiencia Provincial de Las Palmas de Gran Canaria de 12 de junio de 2012, la enfermedad por sí sola no es una causa que pueda acarrear la responsabilidad de los organizadores del viaje, puesto que es una circunstancia que no se puede en principio prever ni superar a pesar de haber puesto toda la diligencia necesaria. Para generar responsabilidad, sería preciso acreditar que la enfermedad se hubiera producido por una causa imputable al organizador o al detallista, circunstancia que no se daba en el caso concreto, en el que el viajero sufrió una intoxicación alimentaria en el que no tuvo nada que ver el proveedor de los servicios.

Pero este criterio no sólo se tiene en cuenta para quienes enferman en el transcurso del itinerario contratado. También resulta de aplicación a quienes realizan un viaje padeciendo una enfermedad crónica y empeoran del mismo, o sufren una recaída. De tal forma, la Sentencia de la Audiencia Provincial de Valencia de 9 de noviembre de 2015 atendió el caso de un menor que sufrió un ataque de ansiedad a bordo de un crucero, del que ya había sido objeto de tratamiento anterior. En este caso, el juzgador entendió que no se puede exigir al organizador más que una respuesta médica adecuada, tal y como se había dado en el caso concreto, por lo que no cabía reproche alguno a los organizadores del viaje.

\footnotetext{
${ }^{43}$ Extractado de las condiciones generales de un contrato de viaje combinado: "(el turoperador) entiende que el viajero es consciente del esfuerzo que puede suponer un viaje de estas características, que se realiza por tierra en su mayor parte, por carreteras y caminos en muchas ocasiones en malas condiciones, pudiendo presentarse dificultades y estando expuesto a sufrir contratiempos y adversidades, como pueden ser: escasa variedad alimenticia, climatología, averías y diversas situaciones difíciles y extremas, donde el cansancio y desánimo físico y moral pueden hacerse presentes", a lo que añade "(el turoperador) entiende, por tanto, que el viajero es consciente de los riesgos que puede correr, como pueden ser entre otros: fuerzas de la naturaleza, enfermedad, accidente, picaduras venenosas (arácnidos o reptiles), condiciones de vida e higiénicas deficientes, cargas o ataques de animales y en algunas circunstancias, terrorismo, delincuencia y otras agresiones; sabiendo el viajero que es posible que no tenga acceso a una rápida evacuación o asistencia médica adecuada o total". Disponible en: http://www.ratpanat.com/fichas-tecnicas/nepaltibet3aug.pdf. Fecha de consulta: 16 de abril de 2017.
} 
Sin embargo, sí surge la responsabilidad cuando desde la organización no se pone ningún medio de respuesta ante situaciones médicas que puedan surgir, que pueden ser por medio de la contratación con terceros proveedores, o medios propios, como es en el caso analizado por la Sentencia de la Audiencia Provincial de Madrid de 18 de octubre de 2005, en el que pese a que se publicitaba en el folleto la existencia de un médico a bordo de un crucero que se comercializaba, resultó que finalmente no era así, de forma que un pasajero en viaje de crucero falleció a causa de un infarto de miocardio, sin haber recibido asistencia alguna. Según expone el juzgador, la responsabilidad "No puede paliarse por el deteriorado estado de salud, con el que inició su viaje el después fallecido, pues no consta que se le preguntara sobre el mismo ni se le exigiera al contratar condición alguna al respecto"

Sin embargo, la idoneidad de la atención provista por los organizadores y sus agentes deberá evaluarse a la vista de las circunstancias concretas del caso, puesto que resulta evidente que en determinados contextos socio geográficos (selvas, desiertos, países subdesarrollados y en vías de desarrollo) no resulta razonable exigir una atención equivalente a las que en España consideramos mínimas.

Esta situación fue abordada por la Sentencia de la Audiencia Provincial de Barcelona de 15 de noviembre de 2016, en la que se tuvieron que ponderar las especiales circunstancias que concurrían en el caso ${ }^{44}$, que permitían advertir que las posibilidades de atención al viajero eran reducidas, no apreciándose falta de diligencia alguna por parte de la entidad demandada, que proporcionó al actor toda la asistencia y atención de que disponía.

Otra de las circunstancias más habituales en los viajes combinados, en las cuales los consumidores necesitan recibir asistencia es ante la presencia de inclemencias climatológicas extremas, de forma que cuando se está ante uno de estos fenómenos (huracanes, tifones, terremotos), la obligación del organizador y sus representantes y proveedores presentes en el lugar en que acaecen es colaborar en la seguridad de los viajeros, de tal forma que cuando estos son "abandonados a su suerte", en términos empleados por la Sentencia de la Audiencia Provincial de La Coruña de 7 de abril de 2011, surge la obligación de indemnizar.

La colaboración en materia de seguridad no debe limitarse a medidas paliativas de los efectos de la situación surgida, sino que debe ir más allá, de forma que si, en la medida de los recursos disponibles, resulta posible modificar el itinerario previsto, protegiendo con ello a los viajeros, no cabrá reproche alguno a la organizadora ni sus agentes, debiendo limitarse a reembolsar a los consumidores los importes correspondientes a las excursiones no efectuadas, según se afirma en la Sentencia de la Audiencia Provincial de Madrid de 1 de octubre de 2013, ante unos cambios en la ruta contratada ocasionados por la concurrencia de un tifón.

A la vista de lo expuesto, es claro que la pretensión del legislador es evitar la situación de desamparo del viajero ante circunstancias que le acaezcan de forma repentina e inesperada, por lo que para ello la norma general supone que los costes que implica la asistencia al viajero le corresponda asumirlos al organizador, si bien, como ya se ha expuesto, en el caso de que su causación fuera imputable al viajero, será éste el que deberá asumirlos. A su vez, esta asistencia deberá ser adecuada a las circunstancias que la ocasionan, de tal forma que la falta

\footnotetext{
${ }^{44} \mathrm{Al}$ tratarse de una competición ciclista amateur en el desierto de Marruecos, se trataba de una prueba en condiciones extremas, con un deficitario estado de las carreteras, disponiendo de limitados medios técnico- médicos disponibles), en el que se había puesto a disposición del viajero el equipo médico contratado por la organización del evento (que incluía un cirujano si bien no especializado en la dolencia ocasionada al viajero por el accidente).
} 
de asistencia no les suponga a los viajeros un padecimiento adicional al generado por el propio suceso.

\section{LOS SERVICIOS DE VIAJES VINCULADOS}

Antes de delimitar el régimen de responsabilidad y asistencia a los viajeros que contratan los servicios de viaje vinculados, se debe comenzar efectuando una breve delimitación de la figura, en los términos previstos en la Directiva europea. El desarrollo de Internet ha propiciado que cada vez más consumidores confeccionen por si mismos sus viajes, valiéndose para ello de herramientas electrónicas que les permiten encontrar la oferta más favorable, como las aplicaciones y páginas Web conocidas como metabuscadores o comparadores de precios, o bien reservando los servicios turísticos directamente con su proveedor o por medio de una agencia de viajes on line.

Básicamente, se trata de procesos de contratación en los que el consumidor selecciona una serie de servicios que son puestos a su disposición por el operador de la página web, en los que necesariamente se incluyen el transporte o el alojamiento, que se combinan para el mismo viaje o vacación. Esta nueva realidad ha pasado a quedar plasmada en la Directiva bajo la denominación de "servicios de viaje vinculados", solventando de esta forma un vacío normativo existente hasta la fecha, puesto que ni la anterior Directiva 90/314/CEE ni el TRLGDCU disponían de una regulación actualizada de los paquetes dinámicos de turismo.

Conforme al art. 3.5 de la Directiva, los empresarios, que son operadores turísticos de cualquier tipo, facilitan de manera presencial o en línea a los viajeros la contratación de servicios, llevándoles a celebrar contratos con distintos prestadores, inclusive mediante procesos de reserva conectados, que no presentan las características de los viajes combinados ${ }^{45}$. Se diferencian de los viajes combinados en que mientras que en éstos existe un único responsable de la ejecución del viaje en su conjunto, en los servicios de viaje vinculados existe una pluralidad de sujetos, que son únicamente responsables de la prestación de su propio servicio.

Tratándose de una figura distinta a la de los viajes combinados, el régimen de obligaciones es también muy diferente. El punto de partida se halla en que el régimen de responsabilidad por el cumplimiento defectuoso de los servicios de viajes vinculados se ha de aplicar en función de la norma que regule el contrato que se suscribe (alojamiento, transporte, etc.), de forma que la única obligación que asume el empresario que facilita los servicios de viaje vinculados es la de constituir "una garantía para el reembolso de todos los pagos que reciban de los viajeros, en la medida en que un servicio de viaje que forme parte de unos servicios de viaje vinculados no se ejecute como consecuencia de la insolvencia del empresario", conforme al art. 19.1 de la Directiva. Además, este mismo precepto añade que"Si dichos empresarios son la parte responsable del transporte de pasajeros, la garantía

\footnotetext{
${ }^{45}$ Esto se produce cuando, tras obtener un servicio turístico de un prestador ( p. ej., un billete de avión), al consumidor se le oferta contratar otro servicio (como el de alojamiento), y su nombre, datos de pago y dirección de correo electrónico son transferidos de un proveedor a otro, y los contratos se celebren en menos de 24 horas.
} 
cubrirá también la repatriación de los viajeros". Dichas garantías operan de forma similar al actual art. 163 TRLGDCU $^{46}$.

Una de las preocupaciones del legislador europeo es que a quien contrata, especialmente si es por medios electrónicos, le quede claro que no le aplica la regulación de los viajes combinados. Es por ello que el art. 19.2 de la Directiva impone al empresario que facilita servicios de viaje vinculados informar al consumidor, "antes de que el viajero quede obligado por cualquier contrato", de forma clara, comprensible y destacada que no está contratando un viaje combinado, y que, por consiguiente, no puede acogerse a ninguno de los derechos que se aplican exclusivamente. También deberá informar al viajero de que goza de la citada protección frente a la insolvencia.

En caso de que el empresario que facilita servicios de viaje vinculados no haya cumplido con los requisitos de información al consumidor impuestos por la norma, resultará de aplicación la previsión del art. 19.3, por el cual "se aplicarán los derechos y obligaciones establecidos en los arts. 9 y 12, y en el capítulo IV, en relación con los servicios de viaje que forman parte de unos servicios de viaje vinculados".

En cuanto a la legislación española, lo cierto es que hasta que no se efectúe la trasposición de la regulación europea, no existirá una norma específica sobre viajes vinculados. Así, se pueden encontrar Sentencias como la de la Audiencia Provincial de Santa Cruz de Tenerife de 5 de octubre de 2016, en el que se limitaba a afirmar que no corresponde aplicar al caso la regulación de los viajes combinados presente en la TRLGDCU -en concreto, en una reclamación frente a una agencia de viajes por los daños derivados de la incorrecta prestación de los servicios e instalaciones de un alojamiento contratado-, puesto que la contratación del vuelo y el alquiler del vehículo lo habían efectuado con empresas diferentes.

\section{CONCLUSIONES}

En la actualidad la programación y venta de viajes combinados se rige en España por el TRLGCDU, cuyo contenido deberá ser modificado en breve, ante la aparición de la nueva Directiva de la Unión Europea2015/2302/UE, que ha venido a introducir una serie de cambios en la regulación existente.

Particularmente, ha sido objeto de análisis a lo largo del presente texto el estatuto relacional entre los organizadores, que elaboran el contenido de los viajes combinados, las agencias de viajes que los comercializan, y los viajeros que hacen uso de ellos. Concretamente, se ha estudiado la modulación de la responsabilidad por las distintas posibilidades de cumplimiento deficiente del contenido del viaje combinado, así como el régimen de asistencia a los viajeros cuando estos se encuentran ante dificultades sin mediar responsabilidad del turoperador ni la agencia.

Como principio general, puede afirmarse que quien contrata con una agencia un servicio de viaje combinado tiene derecho a ser resarcido de todo incumplimiento del servicio contratado por causa que no pueda ser imputable a él mismo.

${ }^{46}$ GONZÁLEZ CABRERA, I., “¿Estamos ante el mismo producto si se adquiere en línea un viaje combinado o distintos servicios de viaje vinculados?", en Revista de Derecho Civil, Vol. III, n 3 (julio-septiembre), 2016. 
Durante largo tiempo, la doctrina y la jurisprudencia no eran unánimes en el reparto de responsabilidades entre turoperadores y agencias de viaje. Si bien la mayoría se mostraban partidarios de un régimen de responsabilidad solidaria, también había una parte significativa que consideraba que se trataba de responsabilidad mancomunada. Ante la diversidad de sentencias, fundamentalmente dentro de la denominada jurisprudencia menor, el Tribunal Supremo se manifestó en la Sentencia de 20 de enero de 2010, empleando los siguientes términos: “(...) la responsabilidad del mayorista u organizador es solidaria con el minorista o agente de viajes frente al consumidor, sin perjuicio de las acciones de regreso que existan entre ellos (...)".

Claramente, la posición adoptada por el Alto Tribunal era que deben responder por un incumplimiento todos aquellos que se benefician del precio pagado, como son tanto el minorista que recibe el encargo, como el mayorista que oferta el servicio y por cuya mediación se realiza. En consecuencia, el cliente, usuario y consumidor del producto, que resulta perjudicado por el servicio contratado, puede dirigir su acción contra cualquiera de ellos, sin perjuicio del derecho de repetición.

Esta posición fue incorporada en el TRLGDCU, cuyo art. 162 permite al consumidor dirigir su acción frente a cualquiera de los obligados y fundamentalmente, frente a aquél con quién directamente contrató el viaje, que por regla general será la agencia de viajes detallista, sin perjuicio de que ésta pueda, después, dirigirse contra los demás obligados por los incumplimientos derivados de sus propios ámbitos de gestión.

Este régimen de responsabilidad es demostrativo del principal objetivo que persigue la regulación de los viajes combinados en el ámbito europeo, y más concretamente, en el español: la protección de los consumidores ante cualquier defecto en la ejecución del contrato, en la búsqueda de que la reparación se obtenga lo más rápidamente posible -idealmente, in situ-, sobre todo teniendo en cuenta la situación de especial debilidad de los viajeros, a quienes las incidencias les suelen acaecer muy lejos de sus casas, y en muchas ocasiones en países en los que la cobertura legal, sanitaria y de protección alcanza unos estándares muy inferiores a los que estamos acostumbrados los consumidores europeos.

Este desequilibrio se ve incrementado a su vez por la propia complejidad del régimen relacional que se encuentra el viajero durante su itinerario, en el que se ve atendido por una multiplicidad de prestadores de servicios ajenos al contrato, que contactan con él con diversa intensidad y a muy distintos niveles, dificultándole enormemente la posibilidad de indagar quién es imputable del incumplimiento.

Por esto mismo, la nueva Directiva vendrá a modificar el régimen para el organizador de un viaje combinado, que le obliga a prestar asistencia a cualquier viajero que se encuentre ante una situación de dificultad sin necesidad de que medie una ejecución defectuosa del contrato. Incluso en esta circunstancia, la normativa le obliga a colaborar en el alojamiento del viajero afectado, así como el regreso a su domicilio, sin que ello implique coste adicional para el consumidor. La única salvedad se encuentra en el caso de que medie responsabilidad del propio viajero, en cuyo caso subsistirá la obligación de ayudarle, si bien repercutiéndole el importe de los gastos abonados para tal ayuda, modificando de esta forma la actual regulación, que permitía al organizador desentenderse del viajero si se daba este caso.

Por último, se ha abordado una nueva realidad existente en el tráfico jurídico, que ha sido recogida por primera vez en la Directiva 2015/2302/UE, como es el de los servicios de viaje vinculados -también conocidos como paquetes dinámicos-, que son los distintos contratoscon diferentes prestadores de servicios (transporte, hotel, alquiler de vehículos...) 
para un mismo viaje o vacación, partiendo de una misma página Web de origen, que ofrece un link con cada uno de ellos.

Estas situaciones se diferencian de los viajes combinados en que mientras que en éstos últimos existe un único responsable de la ejecución del viaje en su conjunto, en los servicios de viaje vinculados hay una pluralidad de sujetos, y cada uno de ellos es únicamente responsable de la prestación de su propio servicio.

En el caso de los servicios de viaje vinculados, la norma se limita a obligar a los empresarios a que informen a los viajeros de que no están contratando un viaje combinado, así como que los prestadores de servicios únicamente son responsables de la correcta ejecución de sus propios contratos.

En estos casos, los empresarios que faciliten servicios de viaje vinculados únicamente deberán prestar protección frente a la insolvencia para la devolución de los pagos que perciban, así como, en la medida en que sean responsables del transporte de pasajeros, para la repatriación de estos, debiendo informar a los viajeros en consecuencia.

En definitiva, el análisis del conjunto de normas que regulan el régimen de responsabilidad y asistencia de mayoristas y minoristas de los viajes combinados frente a los viajeros, permite apreciar que tanto el legislador como la doctrina y la jurisprudencia han optado por la defensa de la posición del viajero frente a la fortaleza del organizador del viaje $\mathrm{y}$, en menor medida, de la agencia de viajes.

\section{BIBLIOGRAFÍA}

ALGABA ROS, S., "La responsabilidad solidaria de organizadores y detallistas frente al consumidor en el contrato de viaje combinado: comentario a la STS de 20 de enero de 2010 (RJ 2010, 158)”, en Revista Aranzadi de derecho patrimonial, nº 25, Cizur Menor, 2010.

ÁLVAREZ RUBIO, J., “Ante la posible reforma del régimen jurídico del viaje combinado en la Unión Europea", en Álvarez Rubio, J. (Coord.) y Tomillo Urbina, J.L. (Dir.), La protección jurídica de los consumidores como motor de desarrollo económico: (Actas del II Congreso Euroamericano de Protección Jurídica de los Consumidores), Ed. Civitas, Madrid, 2011.

ARCARONS I SIMÓN, R. y CASANOVAS IBÁÑEZ, O., "De la jurisprudencia amenazante a la legislación atenazante: análisis del Real Decreto Legislativo 1/2007, de 16 de noviembre, y su incidencia en la organización, programación y venta de viajes combinados", en Revista Aragonesa de Administración Pública, $\mathrm{n}^{\mathrm{o}}$ 32, 2008.

BERENGUER ALBALADEJO, C., "Luces y sombras de la nueva Directiva (UE) 2015/2302 del Parlamento Europeo y del Consejo, de 25 de noviembre de 2015, relativa a los viajes combinados y a los servicios de viaje vinculados", en International Journal of Scientific Managment Tourism, Vol. 2, $\mathrm{n}^{\mathrm{o}}$ 2, 2016.

CAMACHO PEREIRA, C., "La protección del viajero en la directiva (UE) 2015/2302 del Parlamento Europeo y del Consejo, de 25 de noviembre 2015, relativa a los viajes combinados y a los servicios de viaje vinculados", en El turismo y la experiencia del cliente: IX jornadas de investigación en turismo, JIMÉNEZ CABALLERO, J.L. (Dir.), Sevilla: Facultad de Turismo y Finanzas, 2016. 
CAMACHO PEREIRA, C. "La información precontractual en el ámbito de los viajes combinados tras la Directiva (UE) 2015/2302 del Parlamento europeo y del Consejo, de 25 de noviembre de 2015 , relativa a los viajes combinados y a los servicios de viaje vinculados", en Revista de Derecho UNED, $\mathrm{n}^{\circ}$ 19, 2016.

COMITÉ ECONÓMICO Y SOCIAL EUROPEO (CESE). Opinion of the European Economic and Social Committee on the Proposal for aDirective of the European Parliament and of the Council on package travel and assisted travel arrangements, amending Regulation (EC) $N^{o}$ 2006/2004, Directive 2011/83/EU and repealing Council Directive 90/314/EEC. $\operatorname{COM}(2013) 512$ final-2013/0246 (COD). Bruselas, 11 de diciembre de 2013.

GÓMEZ LOZANO, Mª M. y GONZÁLEZ CABRERA, I., El concurso de acreedores en el ámbito turístico, Monografía Depto. Derecho Universidad de Almería, 2014, http://hdl.handle.net/10835/3522.

GONZÁLEZ CABRERA, I., “Estamos ante el mismo producto si se adquiere en línea un viaje combinado o distintos servicios de viaje vinculados?", en Revista de Derecho Civil, Vol. III, $\mathrm{n}^{\mathrm{o}} 3$ (julio-septiembre), 2016.

GONZÁLEZ FERNÁNDEZ, Ma B., "Redefiniciones y armonización en materia de viajes combinados", en Revista de Derecho Mercantil, no 297, 2015.

LUQUE JIMÉNEZ, $\mathrm{M}^{\mathrm{a}}$ C., "Vacaciones frustradas: Análisis del incumplimiento y responsabilidad", en Nuevas perspectivas del turismo para la próxima década: III Jornadas de Investigación en Turismo, por JIMÉNEZ CABALLERO, J.L. y DE FUENTES RUIZ, P. (Coord.), Ed. Digital@tres, Sevilla, 2010.

MARTÍN ARESTI, P., "Directiva (UE) 2015/2302, de 25 de noviembre, del Parlamento Europeo y del Consejo, relativa a los viajes combinados y a los servicios de viaje vinculados, por la que se modifican el Reglamento (CE) n. ${ }^{\circ}$ 2006/2004 y la Directiva 2011/83/UE del Parlamento Europeo y del Consejo y por la que se deroga la Directiva 90/314/CEE del Consejo [DOUE L 326, de 11-XII-2015]", en Crónica de legislación mercantil (Enero-Junio 2016) Ars Iuris Salmanticensis, vol. 4, diciembre 2016, Ediciones Universidad de Salamanca, pág. 131-136.

MARTÍNEZ ESPÍN, P., La reforma del artículo 163 TRLGDCU por la Ley de Jurisdicción Voluntaria, en Blog CESCO.

MARTÍNEZ ESPÍN, P., "Responsabilidad en el contrato de viaje combinado. La solución definitiva. Comentario a la STS de 20 de enero de 2010", en Revista CESCO de Derecho de Consumo, $\mathrm{n}^{\mathrm{o}} 2 / 2012$.

MARTÍNEZ ESPÍN, P., "Viaje combinado: Responsabilidad de agencia de viajes por naufragio del buque. Audiencia Provincial de Madrid (Sección 9a) Sentencia núm. 607/2012 de 28 diciembre (JUR\2013\66472)", en Notas jurisprudenciales CESCO de Derecho de Consumo, 2013.

MOYA JIMÉNEZ, A., Reclamaciones de derecho de consumo. Aspectos prácticos, Ed. Wolters Kluwer, Hospitalet de Llobregat, 2016.

PETIT LAVALL, M ${ }^{\mathrm{a}} \mathrm{V}^{\mathrm{a}}$., "El reglamento (UE) núm. 1177/2010 y la protección de los pasajeros que viajan por mar", en Revista de derecho del transporte: Terrestre, maritimo, aéreo y multimodal, $\mathrm{n}^{\mathrm{o}}$ 12, 2013. 
SÁNCHEZ CALERO, F. (Actualizado por SÁNCHEZ- CALERO GUILARTE, J.) Principios de Derecho Mercantil, 22 $2^{\mathrm{a}}$ Edición, Ed. Thomson Reuters Aranzadi, Cizur Menor, 2017.

ZUBIRI DE SALINAS, M., "La responsabilidad del transportista de personas en los reglamentos comunitarios relativos al transporte aéreo, ferroviario y marítimo", en Revista de derecho del transporte: Terrestre, marítimo, aéreo y multimodal, $\mathrm{n}^{\circ}$ 4, 2010. 